\title{
Collateral Constraints, Tranching, and Price Bases
}

\author{
Feixue Gong* Gregory Phelan ${ }^{\dagger}$
}

This version: November 9, 2020

\begin{abstract}
Tranching an asset increases its basis; tranching a CDS, as occurs with the CDX index, increases the basis on the underlying asset. We consider a general equilibrium model with collateralized financial promises and multiple states of uncertainty to study how allowing an asset to back multiple financial contracts (i.e., tranching) affects price bases. A positive basis emerges when risky assets and their derivative contracts can be used as collateral for financial promises. We provide an empirical test of our theory using inclusion in the CDX and find that inclusion in the CDX increases the CDS basis.
\end{abstract}

Keywords: Collateral, securitized markets, cash-synthetic basis, credit default swaps, asset prices, credit spreads.

JEL classification: D52, D53, G11, G12.

\footnotetext{
*MIT, email: fgong@mit.edu

${ }^{\dagger}$ Williams College, Department of Economics, Schapiro Hall, 24 Hopkins Hall Drive, Williamstown MA 01267, email: gp 4@williams . edu.

We are grateful for feedback from Nina Boyarchenko, Dan Cao, Matthew Darst, Ana Fostel, Benjamin Hébert, David Love, Alexis Akira Toda, and participants at the Econometric Society 2016 North American Summer Meeting. The views and errors are our own. This paper subsumes material from the earlier working papers "Debt Collateralization, Structured Finance, and the CDS Basis" and "A Collateral Theory of the Cash-Synthetic Basis."
} 


\section{Introduction}

Our paper considers how innovations in the use of collateral can affect the prices of portfolios with identical cashflows-i.e., price bases. Structured credit products tranche collateral into multiple securities and reuse these tranches as an additional layer of collateral to issue more securities. Examples abound, such as asset-backed securities (ABS), collateralized debt obligations (CDOs), and synthetic indices like the CDX, a tradable index of credit default swaps (CDSs). These financial innovations greatly increase the ability of assets to serve as collateral. ${ }^{1}$ We argue that these collateral innovations affect price bases. Consider the CDS basis, which is the difference between the spread on a bond and the premium on a credit default swap protecting that bond. The typical convention is CDS basis equals CDS spread minus bond spread. CDS bases before the crisis, especially on high yield (HY) bonds, were significantly positive with an average HY basis of about 80 basis points. This means that a (nearly risk-free) portfolio of a HY bond with a CDS would be more expensive than purchasing a similar maturity US Treasury. During the crisis the basis became negative, and the post-crisis financial recovery has led to a normalization of the CDS basis around 0 .

Our primary contribution is theoretical. We provide a model that shows that the basis on a risky asset is positive whenever the asset can be tranched into multiple contracts, or when derivative contracts backed by the risky asset can be used as collateral to issue further promises (pyramiding). All else equal, tranching and pyramiding increase bases (other factors may contribute to negative bases). We consider a general equilibrium model with heterogeneous agents and collateralized borrowing following Geanakoplos and Zame (2014). Issuing financial contracts requires using assets as collateral, but cross-netting frictions may limit the number of contracts that a single asset can back (Shen et al., 2014). Some assets can be used to back multiple contracts simultaneously, and this could occur in at least two ways. First, the asset could be used as collateral directly to issue several securities at once (tranching). Second, a financial promise backed by the asset could be used as collateral to back further financial promises (pyramiding). In either case, the original asset is explicitly or implicitly used to back multiple distinct financial contracts. We show that, when considering portfolios with identical payoffs, tranching or pyramiding an asset leads to a

\footnotetext{
${ }^{1}$ See Gorton and Metrick (2009); Fostel and Geanakoplos (2012a)
} 
positive basis on the underlying asset, which is consistent with the empirical facts.

Our theory has implications for how inclusion of bonds in CDX indices affects CDS bases. The CDX index can be tranched into indices with multiple "attachment points," thus increasing the ability of the underlying assets to serve as collateral. Our theory yields two predictions. First, tranching the CDX should create a positive CDS-CDX basis, which is consistent with the data. Second, inclusion in the CDX should increase the CDS basis on underlying bonds, since the CDX index tranches CDS contracts. We provide an empirical test of this prediction using difference-indifferences for contracts included/excluded from the CDX index and show that inclusion increases the CDS-bond basis, consistent with our theory.

\section{Related literature}

Our paper relates to two theoretical literatures: directly to the literature on collateral in general equilibrium, and indirectly to the literature on limits to arbitrage. We discuss the empirical literature in Section 4 when discussing the empirical implications of our theory.

Our model introduces tranching and pyramiding into a model of collateral equilibrium based on Geanakoplos (1997, 2003) and Geanakoplos and Zame (2014). This literature tends to focus on either efficiency or how collateral use leads to negative bases. Geanakoplos and Zame (2013) discuss how using promises to back further promises (what they call pyramiding) can potentially allow the market to achieve efficient allocations. Gottardi and Kubler (2015) show that any Arrow-Debreu equilibrium allocation with limited pledgeability can also be attained at a collateralconstrained financial market equilibrium when all financial securities serve as collateral and financial markets are sufficiently rich in terms of payoffs and collateral requirements. We focus on limited tranching and pyramiding across assets and show that the possibility of pyramiding changes the set of contracts issued so that investors will never issue a promise that cannot later be used as collateral. As a result, pyramiding increases the basis on the underlying asset.

Shen et al. (2014) propose a collateral view of financial innovation driven by the cross-netting friction and show that negative bases emerge. Derivatives allowing investors to "carve out" risks emerge to conserve collateral. As a result, the price of a risky asset is always less than the price of a portfolio replicating it with derivatives (negative basis) because the risky asset requires "too much" collateral for agents to isolate the risks they want. In contrast, we show that the sign of the basis 
can flip (the risky asset can be expensive) with tranching and pyramiding, and we also derive their same result when the risky asset cannot be used as collateral. In essence, we consider when the risky asset can "require less collateral" than alternatives. Tranching and pyramiding are ways of stretching collateral, similar to their insight that financial innovation responds to scarce collateral (see also Gottardi et al., 2019, regarding collateral re-use). Our theory rooted in collateral can explain positive bases by emphasizing financial innovations that stretch collateral.

Fostel and Geanakoplos (2012a) provide an example within a binomial (two state) model where the basis is negative (when the risky asset cannot be used as collateral or can be leveraged but cannot be tranched). In their model, tranching refers to using an asset to issue state-contingent contracts, and it is sufficient for an asset to back a single contract at a time. We define tranching as using an asset to back multiple contracts simultaneously. Tranching and pyramiding are meaningful innovations in our setting with multiple states, and we produce positive bases. ${ }^{2}$

Most theoretical papers explain why non-zero bases can persist once deviations occur. This literature relies on limits of arbitrage conditions in the market to explain the existence of nonzero basis: a "shock" occurs that causes CDS and bond premia to diverge, and the basis persists because arbitrageurs cannot fully arbitrage the difference. Of these limits to arbitrage conditions, the most commonly cited is the existence of limits in firms' funding capacity, which prevents firms from conducting enough trades to eliminate the basis. With this interpretation, differences in cross-sectional bases at different points in time point to variations in funding capacity across firms. Notably, the literature focuses on explaining when bond premia exceed CDS spread, as occurs during crises, but does not typically explain the reverse phenomena, which we do.

Gârleanu and Pedersen (2011) provide a model where margin constraints can lead to pricing differences between two identical financial securities. Negative shocks to fundamentals cause margin constraints bind and differences in margin requirements cause the basis to deviate from zero. Our analysis and results differ from Gârleanu and Pedersen (2011) in several ways. First, in Gârleanu and Pedersen (2011), a basis only occurs when negative shocks cause a funding-liquidity crisis and losses for leveraged agents, while in our model non-zero bases are due to the financial

\footnotetext{
${ }^{2}$ Our paper relates to the literature on collateral equilibria in models with multiple states. See Araujo et al. (2012); Simsek (2013); Toda (2015); Brumm et al. (2015); Gottardi and Kubler (2015); Phelan (2015); Cao (2017); Cao and Nie (2017); Gong and Phelan (2019); Phelan and Toda (2019). Darst and Refayet (2018) study credit default swaps in equilibrium.
} 
environment (assets used as collateral), not the presence of a funding-liquidity crisis. Second, we show that the basis between two assets depends not only on the margin requirements of the assets themselves but also on the margin requirements for derivative debt contracts collateralized by the assets. Relatedly, Oehmke and Zawadowski (2015) show that a negative basis emerges when transaction costs are higher for bonds than for CDS. In our paper, negative bases can persist when risky assets are imperfect collateral, and positive bases can persist even when agents can short assets because the efficient use of collateral is to buy CDS rather than to short assets.

\section{General Equilibrium Model with Collateral}

This section presents the basic general equilibrium model with a rich set of collateralized financial contracts subject to cross-netting frictions. All proofs are in Appendix A.

\section{Time, Assets, and Households}

We consider a two-period, $N$-state general equilibrium model with time $t=0,1$. Uncertainty is represented by a tree with a node $s_{0}$ at $t=0$ and $N$ states $n \in \mathcal{N}=\{1, \ldots, N\}$ at $t=1$. There are $Z$ fundamental assets, indexed by $z \in \mathcal{Z}=\{1, \ldots, Z\}$, which produce dividends of the consumption good at $t=1$. For a generic asset $z \in \mathcal{Z}$, let $d_{n}^{z}$ be the dividend of asset $z$ in state $n$. Each asset trades for a price $p_{z}$ at $t=0$, and we denote the vector of asset prices at $t=0$ by $p$.

We suppose that agents are uniformly distributed on $\mathcal{H}=(0,1)$, that is they are described by Lebesgue measure. (We will use the terms "agents" and "investors" interchangeably.) Agents are risk-neutral and have linear utility in consumption $c$ at time 1. Each agent $h \in(0,1)$ assigns subjective probability $\gamma_{n}(h)$ to the state $n$, and beliefs $\gamma_{n}(h)$ are continuous in $h$. The expected utility of agent $h$ is

$$
U^{h}(c)=\sum_{n=1}^{N} \gamma_{n}(h) c_{n}
$$

where $c_{n}$ is consumption in state $n$.

To ensure that in equilibrium investors' positions are sorted by their level of optimism, we 
suppose agents' beliefs satisfy hazard rate dominance (see also Simsek, 2013; Phelan, 2015):

$$
\text { For all } n \in\{1, \ldots, N-1\} \text {, the ratio } \frac{\gamma_{n}(h)}{\sum_{k=n}^{N} \gamma_{k}(h)} \text { is strictly decreasing in } h \text {. }
$$

This condition implies that $\frac{\sum_{k>n} \gamma_{k}(h)}{\sum_{k \geq N} \gamma_{k}(h)}$ is strictly increasing in $h$, which means more optimistic agents are increasingly optimistic about states above a threshold state $n$. Investors with higher $h$ have uniformly higher marginal utility for consumption in states in which the asset payoff is higher (i.e., they are uniformly more optimistic). This setup is equivalent to a model with finitely many heterogeneous risk-averse agents, where endowments and preferences are such that marginal utilities or "hedging needs" are monotonic and uniformly increasing by state.

Each agent is endowed with $\bar{\theta}^{h} \in \mathbb{R}_{+}^{Z}$ assets at $t=0$ and $e^{h} \in \mathbb{R}_{+}^{N}$ consumption goods at $t=1$. We denote asset holdings at $t=0$ by $\theta^{h}=\left(\theta_{1}^{h}, \ldots, \theta_{Z}^{h}\right) \in \mathbb{R}_{+}^{Z}$, implying no short sales of assets.

\section{Financial Contracts and Collateral}

The heart of our analysis involves contracts and collateral. Agents trade financial contracts at $t=0$. A financial contract $j=\left(A^{j}, C^{j}\right)$, consists of a promised payment $A^{j}=\left(A_{n}^{j}\right)_{n \in \mathcal{N}}$ in terms of the consumption good at $t=1$, and an asset $C^{j}$ serving as collateral backing the promise. Since collateral is the only enforcement mechanism, the financial contract yields $\min \left\{A_{n}^{j}, d_{n}^{C^{j}}\right\}$ in state $n .^{3}$ Agents must own collateral in order to make promises.

Let $\mathcal{J}=\{1, \ldots, J\}$ be the set of all possible financial contracts. Throughout the analysis we suppose the set of contracts $\mathcal{J}$ is a finite (guaranteeing equilibrium existence) but very large set. In particular, we suppose that there are no restrictions on the set of contingent promises available so that agents can issue contracts $j$ with any set of promised payoffs $A^{j}$. Because promises can be state-contingent, without loss of generality we can restrict attention to promises $A_{n}^{j} \leq d_{n}^{C^{j}}$ since promising more is redundant given default.

Each contract $j \in \mathcal{J}$ trades for a price $\pi_{j}$. We denote contract holdings of $j \in \mathcal{J}$ by $\varphi_{j}$, where $\varphi_{j}>0$ denote sales and $\varphi_{j}<0$ denote purchases. The sale of a contract corresponds to borrowing the sale price and the purchase of a promise is equivalent to lending the price in return for the

\footnotetext{
${ }^{3}$ This definition of a financial contract encompasses using a portfolio of assets to back the a promised paymentany promise backed by a portfolio of assets can be constructed with a portfolio of financial contracts, each backed by a single asset.
} 
promise. A position of $\varphi_{j}>0$ units of a contract requires ownership of $\varphi_{j}$ units of the collateral, whereas the purchase of such contracts does not require ownership of the collateral.

We suppose that assets are potentially subject to a cross-netting friction as follows. Asset $z$ can back up to $M_{z}$ contracts simultaneously subject to payment enforceability, i.e. $z$ can back $M_{z}$ contracts $j_{1}, \ldots, j_{M_{z}}$ if $\sum_{m}^{M_{z}} A_{n}^{j_{m}} \leq d_{n}^{z}$ for all $n$. When $M_{z}>1$ we say that asset $z$ can be tranched into multiple securities. ${ }^{4}$ Given a portfolio of financial promises $\Phi$ consisting of contract holdings $\varphi_{j}^{\Phi}$, we define collateral requirement for the portfolio as follows. Let $\Phi(z)$ be the contracts sold in portfolio $\Phi$ that are backed by asset $z$, that is $\Phi(z)=\left\{j \in J: \varphi_{j}^{\Phi}>0, C^{j}=z\right\}$. Let $\chi_{z}(\Phi)$ to be the minimum amount of asset $z$ required to satisfy the collateral requirement for asset $z$ in portfolio $\Phi$. $\chi_{z}(\Phi)$ is the smallest number such that

1. contracts are able to deliver the promised payments backed by the collateral, i.e., for all $n$,

$$
\sum_{j \in \Phi(z)} A_{n}^{j} \cdot \varphi_{j}^{\Phi} \leq \chi_{z}(\Phi) \cdot d_{n}^{z}
$$

2. each unit of $z$ backs at most $M_{z}$ contracts.

$$
\sum_{j \in \Phi(z)} \varphi_{j}^{\Phi} \leq M_{z} \cdot \chi_{z}(\Phi)
$$

Even though promises can be state-contingent, an economy in which fundamental assets can back only one contract at a time cannot implement an Arrow-Debreu equilibrium with limited pledgeability (see Geanakoplos and Zame, 2014; Gottardi and Kubler, 2015). ${ }^{5}$ We take the financial environment as exogenous. The question of how financial institutions determine collateral constraints, while important, is outside the scope of this paper. ${ }^{6}$

\footnotetext{
${ }^{4}$ Note that using an asset $z$ to issue a single contract splits the payoffs to $z$ into two sets of contingent claims: those cash flows defined by the contract, and the residual cash flows that accrue to the holder of $z$ after making the contract payments. Thus, issuing a single contract is akin to tranching $z$ into two sets of payoffs. In contrast, we are interested in when an asset can be tranched into at least 3 sets of cash flows.

${ }^{5}$ Generally, if a contract pays in $K \leq N$ states, then the issuer of the contract retains payments in at least $N-K$ states. Collateral constraints require that in equilibrium some agents must hold "bundles" of Arrow-Debreu securities, which is not required with complete markets-in other words, collateral constraints prevent the complete splitting of asset payoffs into Arrow-Debreu securities. Because of this, tranching is not redundant in equilibrium precisely because it increases the set of contingent payoffs that can be backed by an asset.

${ }^{6}$ For papers that discuss this question, see Calza et al. (2007); Dang et al. (2011); Gennaioli et al. (2013); Gorton and Ordoñez (2014).
} 


\section{Budget Set}

Without loss of generality, we normalize the price of consumption to be 1 in all states of the world. Given asset and contract prices at time 0 , each agent chooses asset holdings and trades contracts $j$ to maximize utility, subject to the budget set

$$
\begin{aligned}
B^{h}(p, \pi)= & \left\{(\theta, \Phi, c) \in R_{+}^{Z} \times R^{J} \times R_{+}^{N}:\right. \\
& \sum_{z \in Z} \theta_{z} p_{z} \leq \sum_{j \in \mathcal{J}} \varphi_{j} \pi_{j}, \\
& \chi_{z}(\Phi) \leq \theta_{z}, \forall z \in \mathcal{Z}, \\
& \left.c_{n}=\sum_{z \in Z} \theta_{z} d_{n}^{z}-\sum_{j \in \mathcal{J}} \varphi_{j} \min \left\{A_{n}^{j}, d_{n}^{C^{j}}\right\}\right\} .
\end{aligned}
$$

Equation (1) states that expenditures on assets purchased cannot be greater than the resources borrowed by selling contracts. Equation (2) is the collateral constraint for contracts backed by fundamental assets, requiring that agents must hold sufficient assets to collateralize the contracts they sell. Equation (3) states that in the final states, consumption must equal dividends of the assets held minus debt repayment. Recall that a positive $\varphi_{j}$ denotes that the agent is selling a contract or borrowing $\pi_{j}$ units of account, while a negative $\varphi_{j}$ denotes that the agent is buying the contract or lending $\pi_{j}$ units of account. Short selling of fundamental assets is not possible $\left(\theta_{z} \geq 0\right)$.

\section{Collateral Equilibrium}

Definition 1. A Collateral Equilibrium in this economy is a set of asset prices, contract prices, asset purchases, contract trades, and consumption decisions all by agents, $\left((p, \pi),\left(\left(\theta^{h}, \Phi^{h}, c^{h}\right)_{h \in \mathcal{H}}\right)\right) \in$ $\left(R_{+}^{Z} \times R_{+}^{J}\right) \times\left(R_{+}^{Z} \times R^{J} \times R_{+}^{N}\right)^{\mathcal{H}}$, such that

1. $\sum_{\mathcal{H}} \theta^{h}=\sum_{\mathcal{H}} \bar{\theta}^{h}$,

2. $\sum_{\mathcal{H}} \varphi_{j}^{h}=0, \forall j \in \mathcal{J}$,

3. $\left(\theta^{h}, \Phi^{h}, c^{h}\right) \in B^{h}(p, \pi), \forall h$,

4. $(\theta, \Phi, c) \in B^{h}(p, \pi) \Rightarrow U^{h}(c) \leq U^{h}\left(c^{h}\right), \forall h$.

Condition 1 is the asset market clearing conditions at time 0 and condition 2 is the market clearing condition for financial contracts. Condition 3 requires that all portfolio and consumption 
bundles satisfy agents' budget sets, and condition 4 requires that agents maximize their expected utility given their budget sets. By the same arguments made in Geanakoplos and Zame (2014), equilibrium in this model exists under the assumptions made thus far.

Our baseline model imposes minimal restrictions on preferences and available contracts. In Appendix $\mathrm{C}$ we characterize equilibrium in an economy where agents are restricted to trading noncontingent debt contracts and credit-default swaps. Even though agents cannot trade a full set of contingent contracts, the results on the basis are identical in this setting.

\section{Theoretical Results}

We now provide the theoretical results regarding investment choices and price bases. We define the basis on an asset $z$ as the difference between the price $p_{z}$ of the asset and the closest price $p(\theta)$ of a replicating portfolio $\theta$ :

$$
\operatorname{Basis}_{z}=p_{z}-p(\theta)
$$

Defining in this order preserves the standard notation based on bond spreads (which move inversely with bond prices) so that a positive basis indicates that the bond is "expensive."

We broadly consider two ways in which assets can have different collateral capacities. First, we consider the case when some assets can be used to directly and simultaneously back multiple contracts (tranching) while others cannot. Second, we consider the case where assets can only back one contract directly at a time, but contracts backed by certain assets can serve as collateral for further contracts (pyramiding). Comparing different assets, the one with the greater collateral capacity has the higher price.

\subsection{Results with Tranching}

We begin by proving a fundamental result about tranching before exploring the implications that tranching has on price bases. In equilibrium, any asset that can be tranched into multiple contracts will be tranched.

Lemma 1 (Tranching). Suppose asset $z$ can be used to issue $M_{z}>1$ contracts simultaneously. Then no agent will buy $z$ and issue fewer than $M_{z}$ contracts. In equilibrium, agents that hold $z$ will issue 
$M_{z}$ contracts.

Intuitively when multiple contracts can be issued, holding an asset and issuing a single contract is inefficient-doing so does not take full advantage of the collateral capacity of the asset. In equilibrium, some agents will always hold asset $z$ and issue $M_{z}$ contracts. Therefore, the cost of $z$ prices in the full collateral ability of $z$; it is too expensive for other agents to hold $z$ and issue fewer than the full set of contracts. Thus, any agents who hold the asset will completely tranche it. With this proposition, we can now state our first asset pricing result.

Proposition 1. Consider two assets $z_{1}$ and $z_{2}$ with identical payoffs and prices $p_{1}$ and $p_{2}$. Suppose that the two assets can back the same contracts but $z_{2}$ can back multiple contracts simultaneously while $z_{1}$ cannot, that is $z_{1}$ cannot be tranched while $z_{2}$ can be tranched. Then $p_{2}>p_{1}$.

The intuition is simple - the asset that can be tranched has greater collateral capacity and this capacity is used by investors in equilibrium; this difference is reflected in the price of the asset. The consequence of Lemma 1 can be used to explain two of the most common asset price bases: (1) the swap basis, which compares the cost of an asset to its corresponding derivative, and (2) the CDS-bond basis, which compares the price of a risk-free asset to the price of a "cash-synthetic portfolio.

Let the dividends for a risky asset $Y$ be ordered $s_{1}<\cdots<s_{N}$ with $s_{N}=1$ the maximum dividend as a normalization with price $p_{Y}$. Let $X$ be a risk-free asset delivering 1 for sure, i.e., $d_{n}^{X}=1$ for all $n$, with price $p_{X}$. We first consider the swap basis: suppose $X$ can be used to issue a promise $j_{Y}$ with price $\pi_{Y}$ that replicates the payoffs to $Y$, so that the promise has payoffs $s_{1}, \ldots, s_{N}$; the asset $Y$ can be tranched but $j_{Y}$ cannot. As a direct consequence from Lemma 1, we can state the following result on the swap basis:

Corollary 1 (Swap Basis). In equilibrium, either $X$ is used to issue a derivative contract replicating $Y$, with price $\pi_{Y}$ and Basis ${ }_{Y}=p_{Y}-\pi_{Y}>0$, or the derivative replicating $Y$ is not traded.

Less obviously, the collateral value of tranching also extends to portfolios of assets. The CDS-bond basis compares the price of a risk-free asset to the price of a "cash-synthetic portfolio" consisting of a risky asset and a CDS on the asset, which pays the difference between the maximum promised payoff and the realized dividend on the asset. Using the same environment as before, 
suppose $X$ can back CDS on $Y$, which delivers $1-s_{n}$ units in $n$. Issuing a CDS without default requires using risk-free asset $X$ requires $1-s_{1}$ units of $X$ and grants the issuer $s_{n}-s_{1}$ units in $n$. If the asset $Y$ can be tranched but $X$ cannot be, then $Y$ will have a positive basis.

Corollary 2 (CDS Basis). Consider two assets $X$ and $Y$ described above. In equilibrium, either $X$ is used to issue a CDS on $Y$, with price $\pi_{C}$, and Basis $Y=\pi_{C}^{Y}-\left(p_{X}-p_{Y}\right)>0$, or CDS are not traded.

There are two ways to create a risk-free portfolio: hold $X$ for a cost $p_{X}$, or hold $Y$ and a CDS together for a cost of $p_{Y}+\pi_{C}$. When $Y$ can be tranched, it is strictly cheaper to get a risk-free portfolio by holding $X$, which cannot be tranched. Indeed, in equilibrium an investor that chooses to hold $Y$ would use it to issue tranches would therefore not choose to also hold a CDS.

Finally, we can also consider the case when CDS contracts themselves can be tranched into further promises, which occurs with CDS indices. Consider two assets $z_{1}$ and $z_{2}$ which are identical in both payoffs and collateral capacity (i.e. can be tranched the same) but suppose that the CDS on $z_{2}$ can be tranched while the CDS on $z_{1}$ cannot $^{7}$. The ability to tranche CDS on $z_{2}$ will increase the CDS-bond basis on $z_{2}$.

Corollary 3. Suppose that $z_{2}$ and $z_{1}$ can be directly collateralized in the same way (i.e. $z_{2}$ and $z_{1}$ can be used to issue the same financial contracts). Suppose that the CDS on $z_{2}$ can be tranched but the CDS on $z_{1}$ cannot be tranched. Then the basis on $z_{2}$ is greater than the basis on $z_{1}$. Furthermore, in equilibrium, the CDS on $z_{1}$ will not be traded.

The payoff to issuing the CDS on $z_{1}$ is the same as the payoff to issuing the CDS on $z_{2}$, but the two have different costs. This is because while the CDS themselves are identical in payoff, the CDS on $z_{2}$ is superior collateral compared to the CDS on $z_{1}$ and must therefore have a higher price. Thus, the investor would strictly prefer to issue the CDS on $z_{2}$ and the CDS on $z_{1}$ would be priced but not traded in equilibrium.

The second part of this result is particularly important because it links to the literature on liquidity and CDS trading (e.g., Oehmke and Zawadowski, 2015). This model provides a novel explanation for how CDS inclusion into structured finance products affects liquidity. In our model, CDS which are poor collateral are not even issued. While the result is very stark given the stylized

\footnotetext{
${ }^{7}$ Tranching the CDS could mean breaking it into one security that pays in some states and another security that pays in others.
} 
nature of our model, the insight is more general: the ability to tranche a contract or to use a contract as collateral will affect the issuance and trade in that contract and investors prefer contracts which are superior collateral. ${ }^{8}$

\subsection{Results with Pyramiding}

We now consider using contracts as collateral for further contracts, as occurs with the creation of CDOs and other structured products. In reality, both of these innovations (tranching and pyramiding) occur and often occur simultaneously. ABS are tranched capital structures in the underlying collateral, and CDOs are tranched capital structures in which the underlying collateral are ABS tranches. Similarly, index CDO tranches fit within our definitions, since underlying collateral (CDS) are tranched simultaneously into multiple indices corresponding to different loss levels.

We first formally extend the model to include pyramiding. Based on an essential equivalence between pyramiding and tranching, we show that our results with tranching all extend to the setting with pyramiding.

\subsubsection{Contracts and Pyramiding}

Suppose that assets can back at most one financial contract at a time, but financial contracts to be used as collateral to issue further promises (we refer to this as pyramiding for the rest of the paper).

We introduce multiple levels of pyramiding inductively. Level-0 contracts are promises using one unit of a fundamental asset as collateral, with the set of contracts denoted by $\mathcal{J}^{0}$. Note as before that an economy with level-0 contracts only cannot implement an Arrow-Debreu equilibrium because a fundamental asset can back only one contract at a time. Because of this, allowing level-0 contingent contracts to serve as collateral is not redundant in equilibrium precisely because it increases the collateral capacity of the underlying asset. Contract collateralization effectively allows a fundamental asset to serve as collateral for multiple contracts- the asset directly backs the level-0 contract, and indirectly backs level-1 contracts, etc.

Level-0 debt contracts in $\mathcal{J}^{0}$ can be used as collateral to issue further contingent promises.

Definition 2. We say the first level of collateralization is the creation of promises $j^{1}$ using $k^{0} \in \mathcal{J}^{0}$

\footnotetext{
${ }^{8}$ See also Fostel and Geanakoplos (2016), who show that investment in risky assets increases when the asset can be used as collateral.
} 
as collateral. Denote the set of contracts at the first level of contract collateralization by $\mathcal{J}^{1}$. We write $j^{1}\left(k^{0}\right)=\left(A^{j^{1}}, k^{0}\right)$ to denote the contract that is traded when an agent holds $k^{0}$ as collateral and promises to pay $A^{j^{1}}$. We denote the act of holding $k^{0}$ and selling $j^{1}$ by $k^{0} / j^{1}$.

For a contract $k^{0}$ to be meaningful collateral for a promise $A^{j^{1}}$ it must be that $A_{n}^{k} \geq A_{n}^{j^{1}}$ because otherwise the payoff to $k^{0}$ would always be less than the promise (equality for all $n$ would render the new promise redundant). Thus, in what follows we will only consider when agents use meaningful collateral to make new promises. The payoffs to $j_{m}^{1}\left(k^{0}\right)$ are the same whenever $k^{0}$ is sufficient collateral, and so we can denote the price of a contract $j_{m}^{1}\left(k^{0}\right)$ by $\pi_{m}^{1}$.

In general, level $L$ contract collateralization is to promise a non-contingent payment using a level $L-1$ debt as collateral.

Definition 3. We say the $L$-th level of contract collateralization is the creation of contracts $j^{L}$ using $k^{L-1} \in \mathcal{J}^{L-1}$ as collateral. Denote the set of contracts at the L-th level of collateralization by $\mathcal{J}^{L}$. We write $j^{L}\left(k^{L-1}\right)=\left(A^{j^{L}}, k^{L-1}\right)$ to denote the contract that is traded when an agent holds $k^{L-1} \in J^{L-1}$ as collateral and promises to pay $A_{n}^{j^{L}}$ in state $n$. The contract delivers $\min \left\{A_{n}^{j^{L}}, A_{n}^{k^{L-1}}\right\}$ in state $n$.

With meaningful collateral, the payoff of any contract is defined by the promise, and we use $\pi_{m}^{L}$ to denote the price of any security $j_{m}^{L}\left(k^{L-1}\right) \in \mathcal{J}^{L}$. With $L$ levels of collateralization, the set of financial contracts is given by $\mathcal{J}=\mathcal{J}^{0} \cup \mathcal{J}^{1} \cup \cdots \cup \mathcal{J}^{L}$. Thus, each additional level of collateralization involves the creation of new contracts and allows all previously existing contracts to be purchased with leverage (by issuing new contracts). The budget set now includes the constraint

$$
\sum_{j=j_{n}^{l}\left(j_{k}^{l-1}\right) \in \mathcal{J}^{l}} \max \left\{0, \varphi_{j_{n}^{l}\left(j_{k}^{l-1}\right)}\right\} \leq \varphi_{j_{k}^{l-1}} \forall l \in 1, \ldots, L
$$

which is the collateral constraint for contracts backed by contracts, up to $L$ levels, which is a parameter of the financial environment.

\subsubsection{Theoretical Results}

There is an essential equivalence between tranching and using contracts as collateral. To see this, consider using an asset $Y$ to issue level- 0 contract $j^{0}$ which is then used as collateral to issue a 
level-1 contract $j^{1}$. The owner of $j^{0}$ yields payoffs $A^{j^{0}}-A^{j^{1}}$. Define a contract $j^{01}$ backed by the asset $Y$ and making promised payoffs $A^{j^{01}}=A^{j^{0}}-A^{j^{1}}$. Then $Y$ can simultaneously be tranched into a contract paying $A^{j^{1}}$ as well as $A^{j^{01}}$. Tranching can implement the same state-contingent payoffs created when $Y$ issues a contract that can then be used as collateral.

However, when contracts are limited in their set of state-contingencies, it is no longer true that tranching can directly implement the same payoffs. As an example, if all contracts are restricted to be non-contingent (debt), then pyramiding creates contingencies via default. Replicating the payoffs created by pyramiding requires tranching an asset into a senior-subordinated capital structure (i.e., contingent payoffs). The equivalence between senior-subordinated tranching and equilibrium payoffs when debt can be used as collateral is completely general (Gong and Phelan, 2019).

Lemma 2 (Pyramiding). Suppose asset z can be used to issue contracts that can be used as collateral. Then no agent will buy $z$ and issue a contract that cannot be used as collateral. In equilibrium, agents holding fundamental assets will issue contracts that can be pyramided to issue more contracts.

This generalizes the result found in Gong and Phelan (2019): when some contracts can be used as collateral, investors will exclusively use assets to issue collateralizable contracts whenever possible. In doing so, investors maximize the capacity of the underlying asset to serve as collateral. The following result generalizing Proposition 1 immediately follows.

Proposition 2. Consider two assets $z_{1}$ and $z_{2}$ with identical payoffs and prices $p_{1}$ and $p_{2}$, but suppose that contracts backed by $z_{1}$ cannot be used as collateral, while contracts backed by $z_{2}$ can be used as collateral. Then $p_{2}>p_{1}$.

Similarly, Corollaries 1-3 generalize to include pyramiding. First, pyramiding affects the swap basis: suppose that contracts backed by $Y$ can be used as collateral; then either $X$ is used to issue a derivative contract replicating $Y$, with price $\pi$ and $\operatorname{Basis}_{Y}=p_{Y}-\pi>0$, or the derivative is not traded. Second, pyramiding affects the CDS basis: consider a risk-free asset $X$ and risky asset $Y$, and suppose that contracts backed by $Y$ can be used as collateral while contracts backed by $X$ cannot; then either $X$ is used to issue a CDS on $Y$, with price $\pi_{C}$ and $\operatorname{Basis}_{Y}=\pi_{C}^{Y}-\left(p_{X}-p_{Y}\right)>0$, or CDS are not traded. 
Finally, differential CDS bases reflect differences degrees of pyramiding. Consider two risky assets $z_{1}$ and $z_{2}$ with identical dividends, and suppose that $z_{2}$ can be collateralized more than $z_{1}$ : if $z_{1}$ cannot be used as collateral, then $z_{2}$ can be used as collateral to issue contracts (and perhaps the contracts can also be collateral); if $z_{1}$ can be used as collateral to issue contracts but these contracts cannot be used as collateral, then contracts backed by $z_{2}$ can be used as collateral. Since the CDS on $z_{1}$ or on $z_{2}$ are identical, they must have the same price. But since $z_{2}$ is superior collateral to $z_{1}$, $z_{2}$ has a greater collateral value than $z_{1}$ and thus has a higher price than $z_{1}$ in equilibrium.

In sum, our results yield two key insights regarding how collateral affects the basis. First, the cash-synthetic basis is a measure of the differential "collateral values" between risky and safe assets. Importantly, this depends on the extent to which downstream contracts backed by the asset can be used as collateral as this changes the degree of indirect promises the asset can back. When risky bonds can be used as collateral, and contracts backed by risky bonds can also be used as collateral for financial contracts, the bond premium is less than the corresponding CDS premium. The positive basis emerges because the asset can be used to issue financial promises with positive collateral value. Accordingly, if the collateral value of the derivative contracts decreases, then the basis for the asset should decrease.

Second, agents value assets based on their abilities to provide payoffs in different states. Assets with the same payoffs but that can be used as collateral for different promises allow different agents to isolate payoffs in states in which their marginal utilities are higher. As a result, agents may not "trade against" the basis even though there is an apparent arbitrage opportunity, but trade to receive their most preferred state-contingent payoffs.

\subsection{Economies with Multiple Bases}

We now consider an economy with a single underlying risky asset and consider CDS on it and on derivative debt. Consider a risky contract $j_{M}$, backed by an asset $Y$, where the maximum payoff to $j_{M}$ is $M$. We introduce a CDS on the risky contract $j_{M}$ and now consider the CDS basis for the risky debt $j_{M}$ and to study the relationship between this basis and the basis for the risky asset. We think of the basis on $j_{M}$ as corresponding to the basis on ABS or CDO tranches, rather than the basis on the underlying pool of collateral. As before, we define the basis on the risky 
contract, denoted Basis $_{M}$, as the difference between the spread on the debt CDS and the bond spread, $\operatorname{Basis}_{M}=\pi^{M}-\left(M p_{X}-\pi_{C}^{M}\right)$, where the basis is defined with $M p_{X}$ to reflect the cost of a risk-free payoff of $M$. Our main result is that $\operatorname{Basis}_{M}$ and Basis $_{Y}$ are never equal. We use the term "double basis" to refer to this phenomenon of two unequal bases occurring in equilibrium for assets with correlated payoffs.

Proposition 3. Consider an economy with $C D S$ contracts $C D S_{Y}$ and $C D S_{M}$, which are backed by safe assets:

1. (Leverage) In an economy with level-0 contracts only, the basis on the risky debt is negative and the basis on the risky asset is non-negative. That is, $\pi^{M}+\pi_{C}^{M}<M p_{X}$ and $p+\pi_{C}^{Y} \geq p_{X}$.

2. (Pyramiding) In an economy with level-1 contracts, the basis on the risky debt is zero and the basis on the risky asset is positive, $\pi^{M}+\pi_{C}^{M}=M$ and $p+\pi_{C}^{Y}>p_{X}$

The intuition for this result is similar to the intuition provided in the previous section. Without pyramiding, $j_{M}$ has no collateral value. However, the asset $X$ is allowed to issue $C D S_{M}$, which gives $X$ higher collateral value relative to $j_{M}$. This results in a negative basis on the risky debt. In the pyramiding economy, $\operatorname{Basis}_{M}=0$ implies that $\operatorname{Basis}_{Y}>0$ since $Y$ always has one more level of collateralization than $j_{M}$. Allowing $j_{M}$ to serve as collateral implicitly raises the collateral value of $Y$, and causes Basis $_{Y}>0$. The basis on the most upstream collateral is greater than the basis on downstream contracts. This occurs because the risky asset $Y$ can always back at least one more level of debt contracts than the risky debt can back, and so the debt has a lower collateral value.

It is clear that the previous results on how tranching and pyramiding affect the basis on fundamental assets $z$ also apply in the same way to the basis on derivative contracts. Thus, bases on derivative contracts are measures of the collateral value of those derivatives.

\section{Empirical Implications and Test}

Our analysis offers testable implications regarding fluctuations in bases. We first discuss empirical implications, some suggestive evidence supporting our theory, and considerations for more careful tests by future research. We then present an empirical test of one of the key predictions using CDX inclusion. 


\subsection{Predictions}

Our theory predicts that tranching or pyramiding increases the CDS basis. Thus, variations in the extent to which funding markets use debt as collateral, or to which structured finance implicitly allows debt to be used as collateral, ought to correspond to variations in the CDS basis.

There are two sets of facts that provide suggestive evidence for the predictions of our model. First, the predictions of our model are broadly consistent with the stylized facts regarding the prevalence and collapse of CDO and structured finance issuance as well as the time series behavior of average bases. Rauh and Sufi (2010) show that low-credit-quality firms are more likely to have a multi-tiered capital structure with subordinated debt. Hence, our model predicts that pre-crisis the HY basis should be larger than IG basis because senior-subordinated capital structures, which implicitly use debt as collateral for debt, increase the basis (post-crisis, funding market freezes disproportionately affected weak collateral, which is why HY bases would turn more negative).

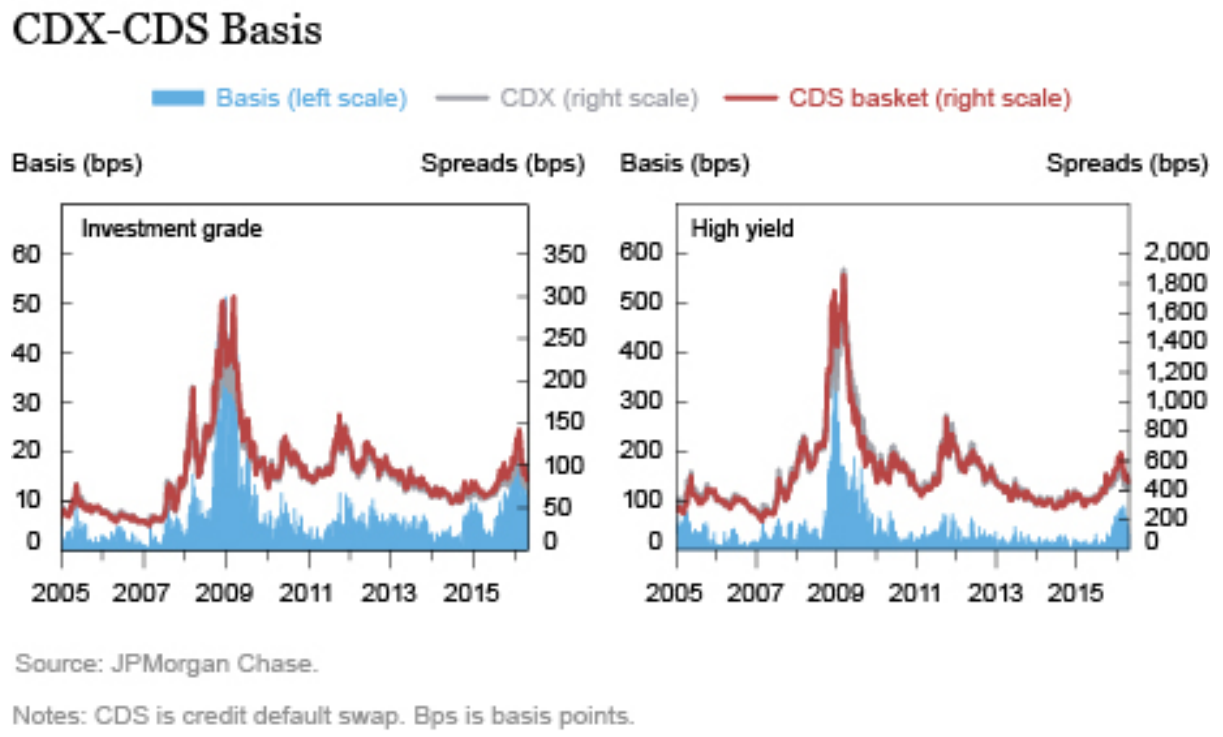

Figure 1: CDS-CDX basis. Source: Boyarchenko et al. (2017)

Additionally, our results from Section 3.3 provide important predictions for CDS contracts that are part of a CDX basis. ${ }^{9}$ The CDX index is tranched into synthetic "index CDO tranches": in addition to buying (or selling) protection on the overall level of the CDX index, investors can also buy protection on the first $3 \%$ of losses among the 125 constituents, or losses between 3 and $7 \%$,

\footnotetext{
${ }^{9}$ We are grateful to Nina Boyarchenko for her comments on this topic.
} 
and so on with attachment points at 10,15, and 30 percent of losses. The CDX tranches correspond to downstream contracts backed by the underlying constituent assets. Because the CDX tranches give greater collateral value to the underlying CDS contracts that make up the index, our theory predicts that the basis on the most upstream collateral-namely, the 125 constituent single name CDS contracts - should be greater than the basis on downstream contracts-namely, the index tranches. ${ }^{10}$ This is exactly what we observe in the data (see Figure 1), with the basis widening when collateral is most scarce, as occurred during the financial crisis. It follows also from Corollary 3 that the CDS-bond basis should increase for CDS contracts that are added to a CDX index. We provide an empirical test of this prediction in the next section.

Our model provides an explanation for CDS bases that is distinct from what exists in the current literature such as the cheapest-to-deliver mechanism"11 or the "CDS market leads the bond market" mechanism. Our theory implies that variations in the extent to which funding markets can use debt as collateral (or the extent to which structured finance implicitly allows debt to be used as collateral) ought to correspond to variations in the CDS basis. In contrast, funding markets for derivative debt securities ought to have no direct effect on the value of the CTD option. Our model also matches the broad time-series data on the CDS-bond basis in a way that the "CDS market leads the bond market" mechanism cannot. ${ }^{12}$

\footnotetext{
${ }^{10}$ Undoubtedly, limits to arbitrage are important for explaining difficulties in exploiting the apparent arbitrage trade of buying protection on the CDX index (pay the premium) and selling protection on the underlying 125 names (receive the higher premium). Our theory suggests that non-arbitrageur investors would trade instead in particular tranches in order isolate precisely the risk profile they desire. For example, see Longstaff and Rajan (2008) for an analysis of how each tranche corresponds to different levels of systemic/correlated default risk.

${ }^{11}$ Blanco et al. (2005) find that the CTD option is most prevalent for European entities because U.S. CDSs have been subject to a Modified Restructuring definition since May 11, 2001, which reduces the value of the delivery option. Blanco et al. (2005) argue that it is almost impossible to value this option analytically since there is no benchmark for the post-default behavior of deliverable bonds. Additional technical considerations of CDS contracts and bond trading can increase the basis (e.g., CDS premia are floored at zero, CDS restructuring clause for technical default, bonds trading below par, see De Wit 2006).

${ }^{12}$ Many authors in the empirical literature have identified factors that partially explain the behavior of the CDS basis. Zhu (2004) finds that the CDS market moves ahead of the bond market in terms of price adjustment because the two markets respond differently to changes in credit conditions, and this timing may explain the existence of non-zero bases in the short run. Blanco et al. (2005) argue that the bond market lags behind the CDS market in determining the price of credit risk, causing short-run deviations in prices; long-run deviations arise from imperfections in CDS contract specification (the CDS price is an upper-bound on credit risk) and from measurement errors, which understate the true credit spread. Nashikkar et al. (2011) show that bonds of firms with a greater degree of uncertainty are expensive (i.e., the basis is positive), which they claim to be consistent with limits to arbitrage theories. Choi and Shachar (2014) argue that a negative basis emerged during the 2008 financial crises because the limited balance sheet capacity of dealer banks prevented corporate bond dealers from trading aggressively enough to close the basis. Bai and Collin-Dufresne (2013) conclude that the basis is larger for bonds with higher frictions, which include trading liquidity, funding cost, counterparty risk, and collateral margin.
} 
We stress that our results about collateral quality provide only one possible explanation of fluctuations in the basis. Our results can begin to explain some of the time-series variation within a collateral class (corresponding to fluctuations in CDO issuance and other structured finance) and some of the cross-sectional difference across classes. One can consider our explanation as having an effect in addition to what liquidity premia would imply. In addition, there have been many other apparent arbitrages that behaved similar to the CDS basis, but for which our story does not apply directly (e.g., cash-futures, mortgage rolls, fed funds, swap spreads, covered interest parity).

\subsection{An Empirical Test}

We now provide a rudimentary test of the hypothesis that inclusion in the CDX (and thus being able to be tranched) should increase the CDS basis, which is the prediction of Corollary 3 . To directly test the effect that collateralizability has on the CDS-bond basis, we look at changes in the CDS-bond basis for CDS contracts that are removed or added to a Markit CDX index. The two Markit CDX indices we consider are the Markit North American High Yield CDX Index, or the CDX.NA.HY Index and the Markit North American Investment Grade CDX Index, or the CDX.NA.IG Index. Markit tranches the HY and IG indices into five and six tranches, respectively, and allows investors to buy shares of the tranches in addition to buying the entire index. Purchasing a tranche of an asset's cash flows is equivalent to funding the asset with some implicit margin (where the margin is given by the prices of the tranches). As a result, the margin requirement increases for entities that are excluded from an index and decreases for entities that are included. For margin-based asset pricing to be valid, the change CDS-bond basis must be positive (negative) for included (excluded) entities relative to unaffected entities.

The details of our empirical analysis are provided in Appendix B, but we provide a summary of the methods and results here. We use a difference-in-difference approach to estimate the percentage change in the CDS-bond basis for credit default swaps that are added to or removed from either index over a two-day window, both around the time of announcement and around the time of index roll, using Markit's publicly available record of changes to the CDX.NA.HY index and CDX.NA.IG index from March 2013 to September 2017. 
The baseline regression estimation is given by equation (6):

$$
\operatorname{basis}_{i t}=\beta_{1} \cdot\left(\operatorname{announced}_{t}\right) \cdot\left(\operatorname{added}_{i}\right)+\beta_{2} \cdot\left(\operatorname{announced}_{t}\right) \cdot\left(\operatorname{removed}_{i}\right)+\gamma \cdot Z_{i t}+\varepsilon_{i t}
$$

where basis $_{i t}$ is the normalized basis for CDS $i$ at time $t$, where the pre-announcement basis is normalized to be 1 . This allows us to estimate the difference in percentages rather than levels. ${ }^{13}$ The variable announced an $_{t}$ an indicator variable that takes a value of 0 before the announcement

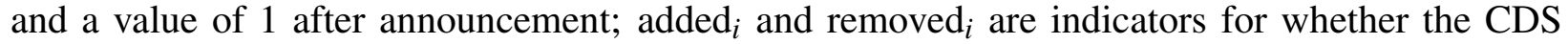
has been added to or removed from an index. If both $\operatorname{added}_{i}=0$ and removed $_{i}=0$, then the CDS was previously included in the index and had no change in status. $Z_{i t}$ consist of a constant term, fixed effect for announcement, fixed effects for addition and removal, year and month fixed effects (the indices are updated twice each year), and indicators for whether the swap switched from one index to another. The coefficient $\beta_{1}\left(\beta_{2}\right)$ is the difference-in-difference estimator that provides the percentage in the CDS-bond basis for entities that were added to (removed from) an index, relative to swaps that remained on the index. Margin-based asset pricing predicts that $\beta_{1}>0$ and $\beta_{2}<0$.

There are two identifying assumptions. First, the announcement of addition or removal from an index is uncorrelated with other factors that may affect the CDS-bond basis. This is likely satisfied because index inclusion does not reveal new information about the CDS, since the requirements for inclusion are publicly available and the characteristics are easily observable. Furthermore, any revealed information which changes the payoff value of the CDS should also be reflected in an equivalent change in the bond price, so that there is no change in the CDS-bond basis.

Second, identification requires common trends across the group - that is, in the absence of announcement, the percentage change in the CDS-bond basis for swaps that were added, removed, or unaffected would have been the same. Since swaps that are included on the index or added to the index have relatively high liquidity and are traded on a frequent basis, nothing fundamentally changes around the announcement date other than information about the swap's inclusion.

\footnotetext{
${ }^{13}$ We use percentage changes because different bonds exhibit a great degree of heterogeneity in the magnitude of the CDS-bond basis. In our sample, the largest bases in absolute value was over 1000 basis points, while the smallest was .5 basis points. CDS contracts with large bases typically were much more volatile in levels. Proceeding with the estimation in percentages reduces the amount of noise. The details of the normalization method can be found in the appendix.
} 
Table 1: The last two specifications include controls for the month and year, as well as indicators for whether the entity switched indices. The month and year controls are not shown in the table.

\begin{tabular}{|c|c|c|c|c|}
\hline & \multicolumn{4}{|c|}{ Dependent variable: Normalized CDS basis (percent changes) } \\
\hline & $\begin{array}{c}\text { announcement } \\
\text { (1) }\end{array}$ & $\begin{array}{l}\text { roll } \\
(2)\end{array}$ & $\begin{array}{c}\text { announcement } \\
\text { (3) }\end{array}$ & $\begin{array}{l}\text { roll } \\
(4)\end{array}$ \\
\hline switch to $\mathrm{HY}$ & & & $\begin{array}{l}0.127^{* *} \\
(0.063)\end{array}$ & $\begin{array}{l}78.159^{* *} \\
(38.689)\end{array}$ \\
\hline switch to IG & & & $\begin{array}{c}0.050 \\
(0.101)\end{array}$ & $\begin{array}{c}17.602 \\
(43.579)\end{array}$ \\
\hline announced $\times$ add & $\begin{array}{l}0.187^{* *} \\
(0.072)\end{array}$ & $\begin{array}{l}-0.128 \\
(0.085)\end{array}$ & $\begin{array}{l}0.183^{* *} \\
(0.073)\end{array}$ & $\begin{array}{l}-29.946 \\
(32.320)\end{array}$ \\
\hline announced $\times$ remove & $\begin{array}{l}-0.071 \\
(0.073)\end{array}$ & $\begin{array}{l}-0.116 \\
(0.086)\end{array}$ & $\begin{array}{l}-0.081 \\
(0.075)\end{array}$ & $\begin{array}{l}-21.873 \\
(33.869)\end{array}$ \\
\hline Observations & 662 & 658 & 662 & 658 \\
\hline $\mathrm{R}^{2}$ & 0.031 & 0.025 & 0.045 & 0.035 \\
\hline Adjusted $\mathrm{R}^{2}$ & 0.023 & 0.018 & 0.027 & 0.023 \\
\hline
\end{tabular}

The result of our baseline procedure is given in Table 1. We find that the announcement of the addition of a CDS to an index is associated with an increase in the CDS-bond basis by about 18 percent, relative to entities that are unaffected (consistent with our theory). In the appendix, we also explicitly test inclusion relative to exclusion (rather than being unaffected) and find that the change in the CDS-bond basis was 26 percent higher for those included than for those excluded. Furthermore, we show that there is no statistically significant percentage change in the CDS-bond basis upon the roll date across the groups.

We also consider the alternative hypothesis that our results are driven by liquidity values, not collateral. It is possible that CDS contracts that are added to an index become more liquid as a result of inclusion, and the increase in the liquidity premium increases only the CDS spread and not the bond spread. However, while trade volumes spike on the roll date of the index, this increase in trade volume is temporary and there is no significant increase in trade volume around the time of the announcement (see Figures 2 and 3). Additionally, since there is no significant change in 


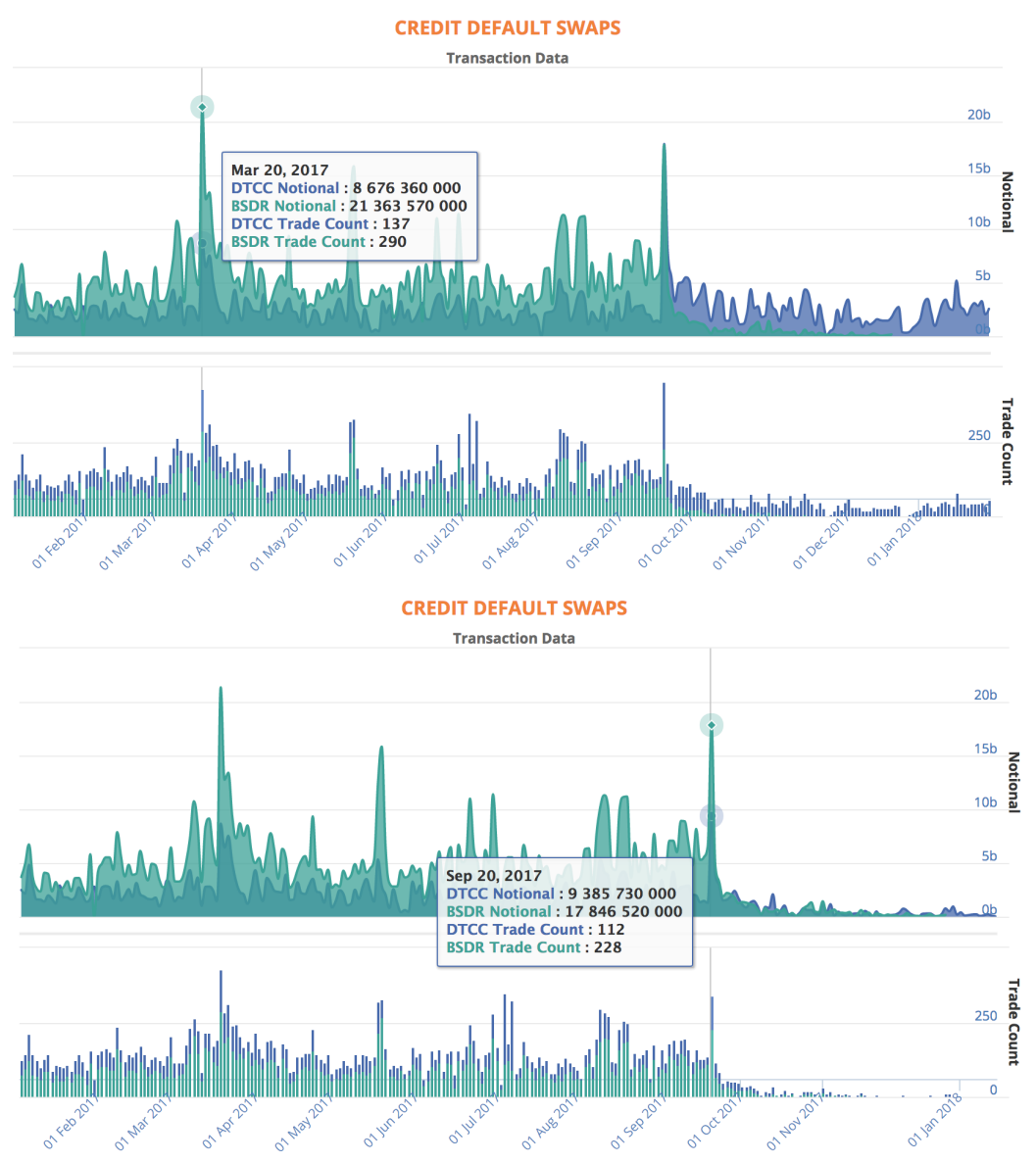

Figure 2: Trade Counts for CDS contracts on IG firms in 2017, with the March and September CDX roll dates highlighted

the CDS-bond basis around the roll date, this suggests that liquidity is not the driving force behind changes in bases. Without a doubt liquidity is an important determinant of asset prices and basis behavior, as is well established in the literature.

In Appendix B, we try to eliminate confounding variables from behavioral responses by market participants and estimate a triple-difference estimation, comparing addition to the HY index to addition to the IG index. The difference between these two indices consist only of (i) credit rating of the firm, which is publicly known prior to announcement (ii) the number of swaps in each index (100 in HY vs 125 in IG) and (iii) the tranching structure of the two indices. While the first difference should not result in any changes to the CDS-bond basis, the latter have implications for the implicit margin requirement and therefore should translate into differences in the percentage change of the CDS-bond basis. We find that inclusion to the HY index (rather than the IG index) 


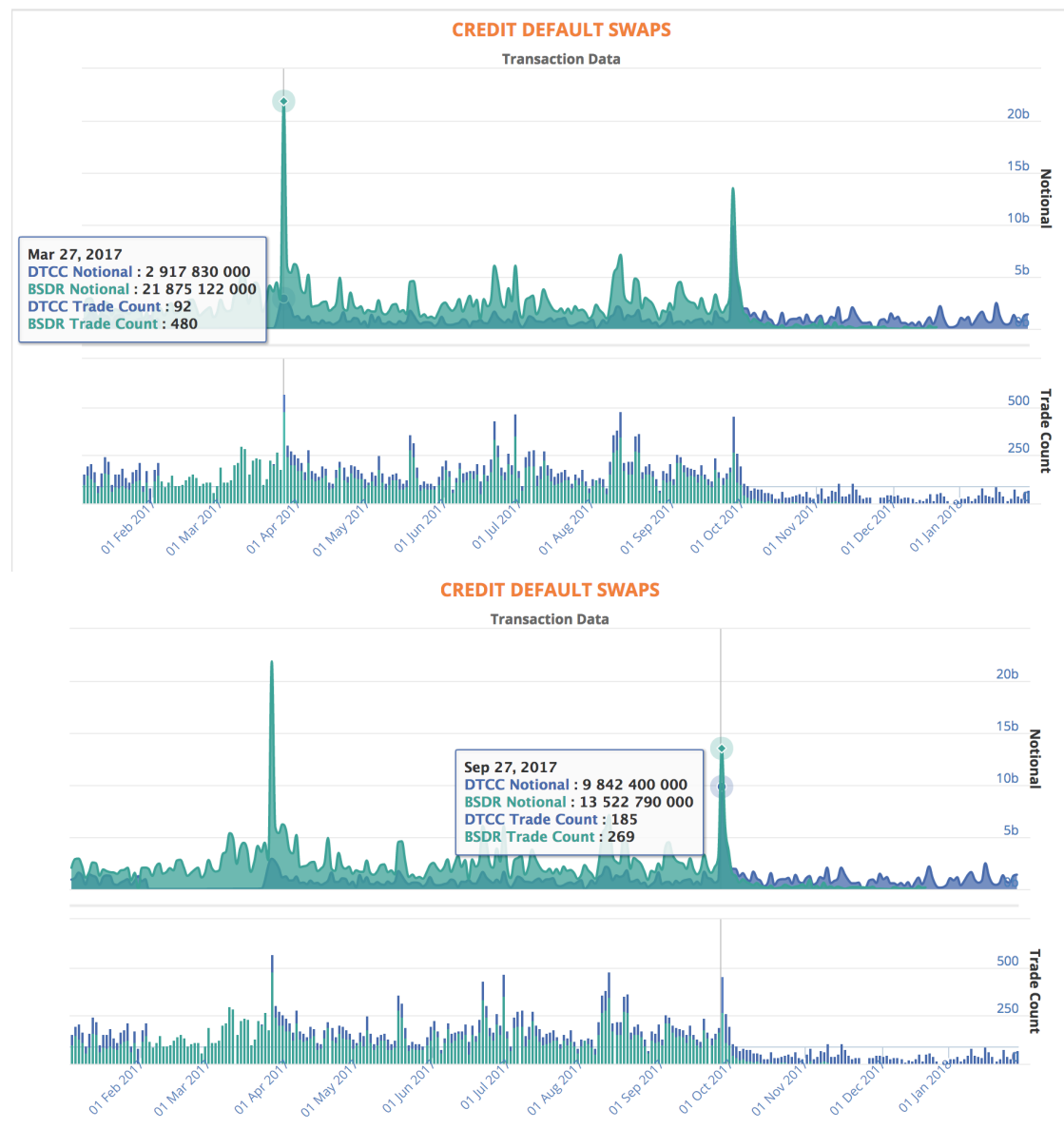

Figure 3: Trade Counts for CDS contracts on HY firms in 2017, with the March and September CDX roll dates highlighted

has significant implications in the movement of the CDS-bond basis. Our results therefore suggest that collateral values, driven by index inclusion, may also be an important determinant.

\section{Conclusion}

We present a theoretical model that relates the extent to which financial markets can effectively use assets as collateral to the CDS basis on those bonds. We show that the basis is positive when either an asset can be tranched into multiple securities or agents can use risky debt contracts as collateral to issue financial promises. Structured finance that uses pools of collateral to issue seniorsubordinated capital structures will produce positive bases on the underlying collateral, and thus financing these assets will be cheap. We also prove that when multiple CDS contracts are traded 
in an economy with tranching or pyramiding, the bases on the CDS contracts must be different as each level of has a different collateral value. We provide empirical evidence for our theory using inclusion/exclusion in CDX indices to show that the behavior of the CDS basis is consistent with our theory.

\section{References}

Araujo, A., F. Kubler, And S. Schommer (2012): "Regulating Collateral-Requirements When Markets Are Incomplete," Journal of Economic Theory, 147, 450-476.

BAi, J. And P. Collin-Dufresne (2013): "The CDS-Bond Basis," American Financial Association 2013 San Diego Meetings Paper.

Blanco, R., S. Brennan, And I. W. Marsh (2005): "An Empirical Analysis of the Dynamic Relation between Investment-Grade Bonds and Credit Default Swaps," The Journal of Finance, 60, 2255-2281.

Bottazzi, J.-M., J. LuQue, And M. R. PÁscoA (2012): "Securities market theory: Possession, repo and rehypothecation," Journal of Economic Theory, 147, 477-500.

Boyarchenko, N., P. Gupta, And J. Yen (2017): “Trends in Arbitrage-Based Measures of Bond Liquidity," Federal Reserve Bank of New York Liberty Street Economics (blog).

Brumm, J., M. Grill, F. Kubler, AND K. Schmedders (2015): “Collateral requirements and asset prices," International Economic Review, 56, 1-25.

Calza, A., T. Monacelli, AND L. StracCA (2007): "Mortgage markets, collateral constraints, and monetary policy: do institutional factors matter?" Collateral Constraints, and Monetary Policy: Do Institutional Factors Matter.

CAO, D. (2017): "Speculation and financial wealth distribution under belief heterogeneity," The Economic Journal.

CAO, D. AND G. NIE (2017): "Amplification and Asymmetric Effects without Collateral Constraints," American Economic Journal: Macroeconomics, 9, 222-66.

Chen, H., G. Noronha, And V. Singal (2004): "The Price Response to S\&P 500 Index Additions and Deletions: Evidence of Asymmetry and a New Explanation," Journal of Finance, 59, 1901-1930. 
Choi, J. AND O. Shachar (2014): "Did Liquidity Providers Become Liquidity Seekers? Evidence from the CDS-Bond Basis During the 2008 Financial Crisis," FRB of New York Staff Report No. 650.

Dang, T., G. Gorton, And B. Holmström (2011): "Ignorance and the Optimality of Debt for Liquidity Provision," Tech. rep., MIT and Yale University.

DARst, R. M. And E. Refayet (2018): "Credit Default Swaps in General Equilibrium: Endogenous Default and Credit-Spread Spillovers," Journal of Money, Credit and Banking, 50, 1901-1933.

DE WIT, J. (2006): “Exploring the CDS-Bond Basis,” National Bank of Belgium Working Paper No. 104.

Denis, D. K., J. J. McConnel, A. V. Ovtchinnikov, And Y. Yu (2003): “S\&P 500 index additions and earnings expectations," Journal of Finance, 58, 1821-1840.

Fostel, A. And J. Geanakoplos (2008): "Leverage Cycles and The Anxious Economy," American Economic Review, 98, 1211-1244.

- (2012a): "Tranching, CDS, and Asset prices: How Financial Innovation Can Cause Bubbles and Crashes," American Economic Journal: Macroeconomics, 4, 190-225.

(2012b): "Why Does Bad News Increase Volatility And Decrease Leverage?" Journal of Economic Theory, 147, 501-525.

(2016): "Financial Innovation, Collateral, and Investment," American Economic Journal: Macroeconomics, 8, 242-284.

GÂRleanu, N. And L. H. Pedersen (2011): "Margin-based Asset Pricing and Deviations from the Law of One Price," Review of Financial Studies, 24, 1980-2022.

Geanakoplos, J. (1997): "Promises Promises," in Santa Fe Institute Studies in the Sciences of Complexity-proceedings volume, Addison-Wesley Publishing Co, vol. 27, 285-320.

- (2003): "Liquidity, Default and Crashes: Endogenous Contracts in General Equilibrium," in Advances in Economics and Econometrics: Theory and Applications, Eight World Conference, Econometric Society Monographs, vol. 2, 170-205.

Geanakoplos, J. And W. R. Zame (2013): “Security Pools and Efficiency,” Mimeo. (2014): “Collateral equilibrium, I: a basic framework,” Economic Theory, 56, 443-492.

Gennaioli, N., A. Shleifer, And R. W. Vishny (2013): “A model of shadow banking,” The Journal of Finance, 68, 1331-1363. 
Gong, F. AND G. Phelan (2019): "Debt collateralization, capital structure, and maximal leverage," Economic Theory, 1-27.

Gorton, G. And A. Metrick (2009): "Haircuts," Yale ICF Working Paper No. 09-15, http: / / ssrn. com/abstract $=1447438$.

Gorton, G. B. And G. Ordoñez (2014): “Collateral Crises,” American Econmic Review, 104, $343-378$.

GotTARdi, P. AND F. KUBler (2015): "Dynamic competitive economies with complete markets and collateral constraints," The Review of Economic Studies, rdv002.

Gottardi, P., V. Maurin, And C. Monnet (2019): "A theory of repurchase agreements, collateral re-use, and repo intermediation," Review of Economic Dynamics.

HARRIS, L. AND E. GUREL (1986): "Price and volume effects associated with changes in the S\&P 500 list: New evidence for the existence of price pressures," the Journal of Finance, 41, $815-829$.

LONGSTAFF, F. A. AND A. RAJAN (2008): "An empirical analysis of the pricing of collateralized debt obligations," The Journal of Finance, 63, 529-563.

Nashikkar, A., M. G. Subrahmanyam, And S. Mahanti (2011): "Liquidity and Arbitrage in the Market for Credit Risk," Journal of Financial and Quantitative Analysis, 46, 627-656.

OEHMKe, M. AND A. ZAWAdOWsKi (2015): "Synthetic or real? The equilibrium effects of credit default swaps on bond markets," Review of Financial Studies, hhv047.

Phelan, G. (2015): “Collateralized Borrowing and Increasing Risk,” Economic Theory, 1-32.

Phelan, G. And A. A. Toda (2019): "Securitized Markets, International Capital Flows, and Global Welfare," Journal Financial Economics, 131, 571-592.

RAuH, J. D. AND A. SUfI (2010): "Capital structure and debt structure," The Review of Financial Studies, 23, 4242-4280.

Shen, J., H. YAn, AND J. ZhANG (2014): “Collateral-motivated financial innovation," Review of Financial Studies, hhu036.

SHLEIFER, A. (1986): “Do demand curves for stocks slope down?” The Journal of Finance, 41, 579-590.

SimseK, A. (2013): “Belief Disagreements and Collateral Constraints,” Econometrica, 81, 1-53. 
TodA, A. A. (2015): “Securitization and Leverage in General Equilibrium," Tech. rep., University of California, San Diego.

Wurgler, J. And E. Zhuravskaya (2002): "Does Arbitrage Flatten Demand Curves for Stocks?" Journal of Business, 75, 583-608.

ZHU, H. (2004): "An empirical comparison of credit spreads between the bond market and the credit default swap market,” Working Paper Bank for International Settlements.

\section{Appendices for Online Publication}

\section{A Proofs}

\section{A.1 Proof of Proposition 1}

Proof. Consider a contract $j_{1}$ backed by $z_{1}$ that is traded in equilibrium at a price $\pi_{1}$. An investor can receive the payoffs $d^{1}-A^{j_{1}}$ by using either asset as collateral to issue the payoffs $A^{j_{1}}$. But by Lemma 1 no investor holding $z_{2}$ would choose to issue $j_{1}$ alone. Since by assumption some investor is holding $z_{1}$ to yield the cash flows $d^{1}-A^{j_{1}}$, but no investor would want to hold $z_{2}$ to hold those same cash flows, it must be that the cost of those cash flows is cheaper when holding $z_{1}$, i.e.,

$$
p_{1}-\pi_{1}<p_{2}-\pi_{1} .
$$

\section{A.2 Proof of Corollary 2}

Proof. Suppose CDS are traded. Using $X$ to issue the CDS yields $s_{n}-s_{1}$ and costs $\left(1-s_{1}\right) p_{X}-\pi_{C}$. However, an investor can yield $s_{n}-s_{1}$ by holding $Y$ and issuing a single risk-free contract that promises $s_{1}$ in each state, which costs $p_{Y}-s_{1} p_{X}$. But since $Y$ has capacity to be tranched further, any investor holding $Y$ would strictly prefer to issue additional contracts, and so $p_{Y}-s_{1} p_{X}>(1-$ $\left.s_{1}\right) p_{X}-\pi_{C}$. Rearranging yields the result. If the basis is otherwise, then no agent would choose to 
use $X$ to issue CDS and would choose instead to use $Y$ to issue contracts.

\section{A.3 Proof of Lemma 2}

Proof. Consider a contract $j_{1}$ with price $\pi_{1}$ such that $A^{j_{1}}<d_{n}^{z}$ for some $n$. Consider a second contract $j_{2}$ with price $\pi_{2}$ that can serve as collateral for $j_{1}$, and the payoffs to $j_{2}$ are not identical to the payoffs for $z$. In other words, an agent can hold $z$, issue $j_{2}$, and receive positive payoffs in at least one state, and another agent can similarly hold $j_{2}$, issue $j_{1}$, and receive positive payoffs in some states.

Let $\gamma^{h}$ denote the vector of subjective probabilities $\left(\gamma_{1}(h), \gamma_{2}(h), \ldots, \gamma_{N}(h)\right)$ for investor $h$. If an investor strictly prefers to hold $z$ and issue $j_{1}$, then given investor preferences we have

$$
\begin{aligned}
& \frac{\gamma^{h} \cdot\left(d^{z}-A^{j_{1}}\right)}{p_{z}-\pi_{1}}>\frac{\gamma^{h} \cdot\left(d^{z}-A^{j_{2}}\right)}{p_{z}-\pi_{2}}, \\
& \frac{\gamma^{h} \cdot\left(d^{z}-A^{j_{1}}\right)}{p_{z}-\pi_{1}}>\frac{\gamma^{h} \cdot\left(A^{j_{2}}-A^{j_{1}}\right)}{\pi_{2}-\pi_{1}},
\end{aligned}
$$

where the numerator of each term is the marginal utility of the investment and the denominator is the price of the investment. The first line says that holding $z$ and issuing $j_{1}$ is preferred over issuing $j_{2}$, and the second line says that holding $z$ and issuing $j_{1}$ is preferred over holding $j_{2}$ and issuing $j_{1}$. Multiplying we have

$$
\begin{aligned}
& \gamma^{h} \cdot\left(d^{z}-A^{j_{1}}\right)\left(p_{z}-\pi_{2}\right)>\gamma^{h} \cdot\left(d^{z}-A^{j_{2}}\right)\left(p_{z}-\pi_{1}\right), \\
& \gamma^{h} \cdot\left(d^{z}-A^{j_{1}}\right)\left(\pi_{2}-\pi_{1}\right)>\gamma^{h} \cdot\left(A^{j_{2}}-A^{j_{1}}\right)\left(p_{z}-\pi_{1}\right),
\end{aligned}
$$

and adding these two inequalities yields

$$
\gamma^{h} \cdot\left(d^{z}-A^{j_{1}}\right)\left(p_{z}-\pi_{1}\right)>\gamma^{h} \cdot\left(d^{z}-A^{j_{1}}\right)\left(p_{z}-\pi_{1}\right)
$$

which is a contradiction. Thus, the agents either prefers issuing the contract $j_{2}$ which can be used as collateral or investing in $j_{2}$ and issuing the contract $j_{1}$. 


\section{B Empirical Test Using Markit CDX Inclusion/Exclusion}

This section describes in greater detail the empirical test of our theory using inclusion and exclusion in Markit CDX indices.

\section{B.1 The logistics of index inclusion/exclusion and index tranching}

The HY (IG) index is composed of 100 (125) liquid North American entities with high yield (investment grade) credit ratings that trade in the CDS market. There are two roll dates every year for both the HY and IG indices, once in March and once in September. The IG index rolls out on September 20 (March 20) and the HY index rolls out on September 27 (March 27). When the 20th or the 27th falls on a non-trading day, the IG and HY indices are rolled out on the trading day closest to the 20th and 27th, respectively. Prior to a new index being rolled out, Markit releases information about which CDS contracts are added to or removed from the CDX index and Markit keeps publicly available records of these announcements from 2013-2017, as well as a finalized list of the CDS basket for each roll.

All CDS contracts in the basket are equally weighted, though Markit does have target sectorspecific weights for the composition of each index. Markit publishes the list of entities removed or added to the indices around a week before the roll date. Entities are removed from the index if any of the following conditions are satisfied

1. There is a corporate event (i.e. merger or acquisition).

2. There is a credit event-the bond matures, is called, or is defaulted upon.

3. For the HY index, the debt outstanding of the entity falls below a certain level; for the IG index, the debt outstanding rises above a certain level.

4. The credit default swap no longer meets the liquidity requirement.

5. The target sector weights in the index are not met; or

6. There is a change in the relevant credit rating. For example, a formerly investment-grade corporation that gets demoted to high-yield would be removed from the IG index to the HY index and vice versa.

Entities are added to the index if

1. the CDS satisfies the liquidity requirement 
2. The referenced corporation meets the required amount of debt outstanding.

Entities are also added or removed from an index based on the results of a dealer poll conducted amongst institutions that frequently trade these indices. Furthermore, the HY and the IG index are tranched separately and the tranches are shown in Figure 4.

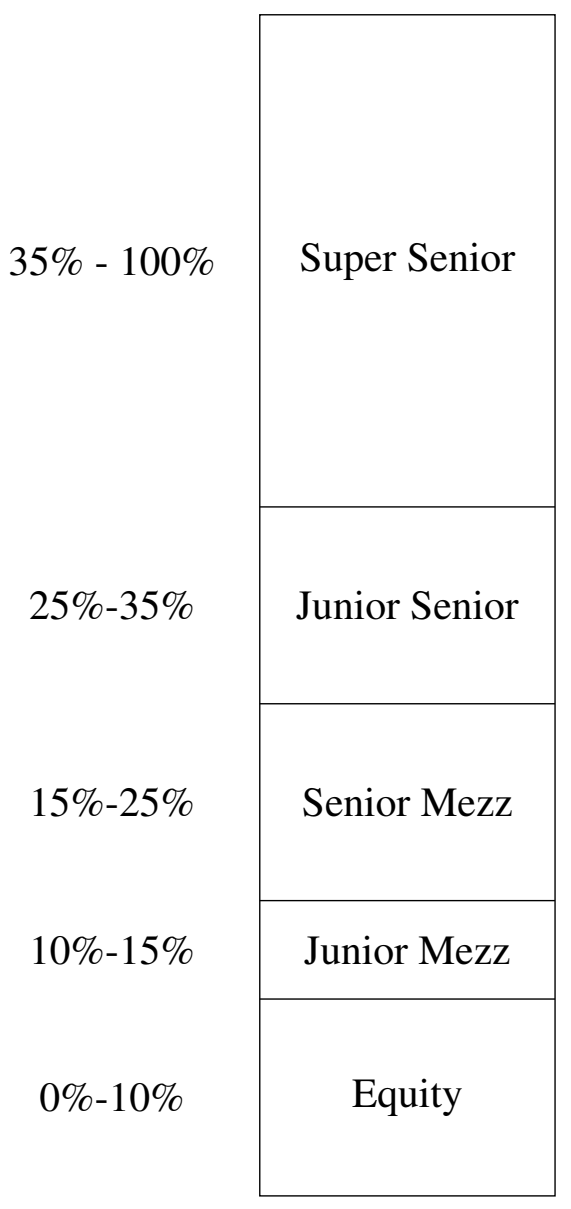

HY tranche

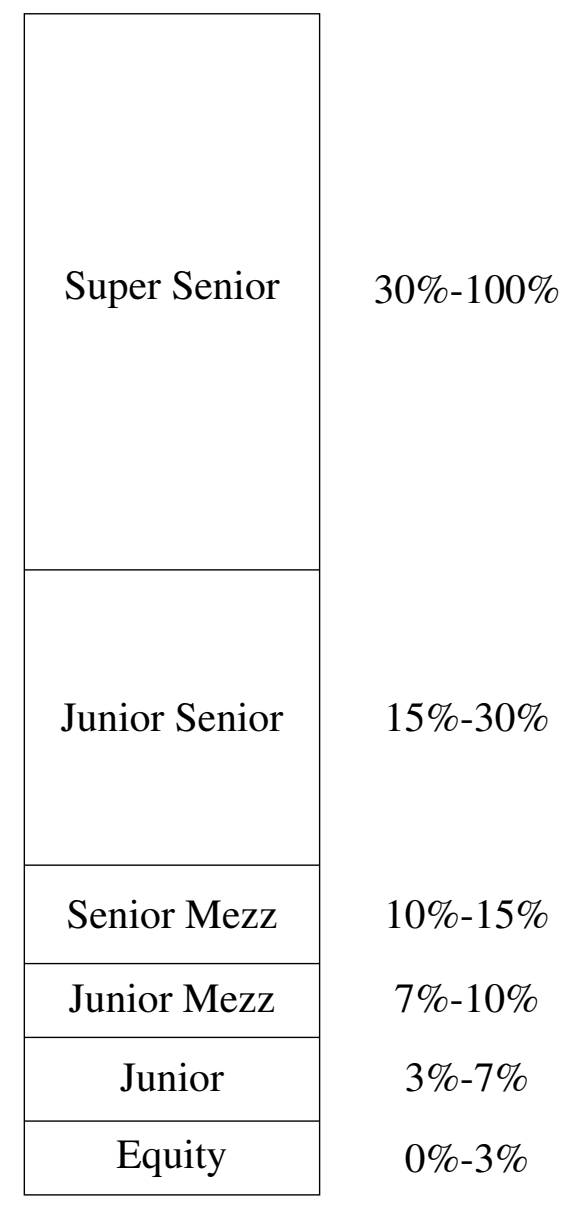

IG tranche

Figure 4: Tranches for HY and IG indices

\section{B.2 Data}

Based on Markit's publicly available record of changes to the CDX.NA.HY index and CDX.NA.IG index from March 2013 to September 2017, we compiled a list of CDS contracts that were included, excluded, or stayed on the index. We exclude contracts that were removed from an index due to a credit event. We obtained end-of-day mid CDS bases from Bloomberg, where the mid CDS basis is defined as the CDS spread minus the Z-spread (zero-volatility spread) for a fixed rate cash bond 
of the same issuer and maturity. The z-spread takes into account the full term structure of the benchmark swap curve and is defined as the spread that must be added to a give benchmark zero swap curve so that the sum of the bond's discounted cash flows equals its price, with each cash flow discounted at its own rate. As such, the Z-spread is a reasonably realistic valuation of a bond's cash flows. We obtained CDS data for all entities that were excluded or included from a roll and a random subsample of entities that were unaffected by the roll.

We group the CDS data into 5 different status categories: included, excluded, updated (removed), updated (added), and remain. Included and excluded observations are self-explanatory, though the sample sizes for these two groups are rather small (approximately 50 observations in each group) because most rolls do not involve substantial changes to the index. A referenced bond has a status of "updated" if the firm has issued another a newer bond with maturity closer to five years. Markit prefers to select newer bonds with a maturity of around five years because five-year CDS contracts are the most commonly traded and are the most liquid on the market.

\section{B.3 Estimation Method}

We use a difference-in-difference approach to estimate the change in the CDS-bond basis for credit default swaps that are added to or removed from either index over a two-day window, both around the time of announcement and around the time of index roll. We use the end-of-day CDS bond-basis the day before the announcement and the day of the announcement (as well as the day before roll and the day of roll). The baseline regression examines percentage changes for the CDSbond basis of CDS contracts that were added, removed, or unaffected by the announcement/roll and does not include observations that were updated.

We use percent changes because different bonds exhibit a great degree of heterogeneity in the magnitude of the CDS-bond basis. In our sample, the largest bases (in absolute value) was over 1000 basis points while the smallest observed basis was 0.5 basis points. CDS contracts with large bases typically were much more volatile in levels, changing by over 200 basis points between trading days. Because of this, running a regression on levels introduces a lot of noise into the estimation. The normalization procedure is as follows: Letting basis ${ }_{0}$ and basis ${ }_{1}$ be the observed 
basis before and after an announcement (or roll). We define

$$
\widehat{\text { basis }_{0}}=1, \quad \widehat{\text { basis }_{1}}=\frac{\text { basis }_{1}-\text { basis }_{0}}{\frac{\mid \text { basis }_{1}|+| \text { basis }_{0} \mid}{2}}
$$

so that the normalized basis before treatment is equal to 1 , and the the after-treatment observation is the percentage change in the basis. To calculate the percentage change in the basis, we divide by the mean of the absolute values of the pre- and post-announcement basis for several reasons

1. Dividing by the absolute value of the pre-announcement (roll) basis or post-announcement (roll) basis introduces systematic bias into the regression. Consider the case when added entities tend to have both positive bases and and experience a increase in basis while removed entities tend to have negative bases and experience a decrease in the basis. Dividing by the pre-announcement basis would upward bias the estimated coefficients while dividing by the post-announcement basis biases the estimates toward zero.

2. We use the mean of the absolute values because there are several observations for which the basis switches signs over the observation period. This is problematic if the mean of the basis is close to zero. ${ }^{14}$

The regression equation is given by

$$
\operatorname{basis}_{i s t}=\beta_{0}+\beta_{1} \lambda_{t}+\beta_{2} \gamma_{a}+\beta_{3} \gamma_{r}+\beta_{4} \lambda_{t} \cdot \gamma_{a}+\beta_{5} \lambda_{t} \cdot \gamma_{r}+\varepsilon_{i s t}
$$

Here, basis ${ }_{i s t}$ is the basis for $\operatorname{CDS} i$ with status $s$ at time $t . \lambda_{t}$ is an indicator variable that takes a value of 0 before the announcement (or roll) and a value of 1 after the announcement/roll. The regression includes dummy variables $\gamma_{a}$ and $\gamma_{r}$ that takes values of 1 if the CDS is in the added or removed group respectively. In this equation, $\beta_{1}$ is interpreted as the time fixed effect and $\beta_{2}$ and $\beta_{3}$ are the status-group fixed effects for entities that are added or removed from an index, respectively. $\beta_{4}$ is the difference-in-difference estimator that provides the level change in the CDS-bond basis around the time of the announcement (or roll) for entities added to an index relative to entities that were unaffected. $\beta_{5}$ is the analogous estimator for entities that were removed from an index

\footnotetext{
${ }^{14}$ An example: a CDS basis switches from -5 to 5.25 during the window of observation. Taking a simple mean mean would inflate the actual change in basis.
} 
relative to swaps that are unaffected. Margin-based asset pricing predicts that $\beta_{4}>0$ and $\beta_{5}<0$. In order for $\beta_{4}$ and $\beta_{5}$ to be interpreted as the causal effect of the implied margin change on the CDS-bond basis, it must be the case that nothing else changed in the included or excluded group at the time of the announcement (or roll) that did not change for the unaffected group.

We rerun the baseline regression including controls for index switching and year-month fixed effects.

$$
\text { basis }_{i s t}=\beta_{0}+\beta_{1} \lambda_{t}+\beta_{2} \gamma_{a}+\beta_{3} \gamma_{r}+\beta_{4} \lambda_{t} \cdot \gamma_{a}+\beta_{5} \lambda_{t} \cdot \gamma_{r}+\beta_{6} \delta_{H Y}+\beta_{7} \delta I G+\alpha T+\varepsilon_{i s t}
$$

$\delta_{H Y}$ is an indicator variable that takes a value of 1 if the entity switched from the IG index to the HY index. $\beta_{7}$ is the analogous variable indicating whether an entity switched from HY to IG. T is a matrix of dummy variables to estimate month-year effects. The results of the two regressions are reported in the next section.

Here, the biggest threat to identification is that the announcement of inclusion or exclusion from an index conveys some information about the bond/CDS or for some other reason causes market participants to treat the bond/CDS contracts differently. Theoretically, index inclusion does not reveal new information about the future prospects of the newly included firm, since the requirements of index inclusion or exclusion are published by Markit and publicly available to all market participants. However, a number of papers have found that inclusion in an equity index is associated with improved stock prices (see Harris and Gurel (1986), Shleifer (1986), Denis et al. (2003), Chen et al. (2004), and Wurgler and Zhuravskaya (2002)). For equities, this change in price can be explained by, among other hypotheses, increased monitoring by investors after inclusion which leads to more effort by the firm's management; increased demand for the equity pushing up prices from funds that track the index; or greater reputation costs if management performs poorly. However, because trading CDS contracts is fundamentally different from trading equities, these hypotheses do not apply to the CDX index. Investors in CDS buy protection against a firm credit default and there is no monitoring incentive involved and funds do not track CDX indices.

This does not exclude the possibility of a behavioral response by market participants when an entity is added to or removed from the index. To eliminate differential changes in behavioral reactions for the included, excluded, and unaffected groups, we run a difference-in-difference-in- 
difference regression on CDS entities that were added to or removed rom the HY and IG indices.

$$
\text { basis }_{i s t}=\beta_{0}+\beta_{1} \lambda_{t}+\beta_{2} \gamma_{a}+\beta_{3} \kappa_{I}+\beta_{4} \lambda_{t} \gamma_{a}+\beta_{5} \lambda_{t} \kappa_{I}+\beta_{6} \gamma_{a} \kappa_{I}+\beta_{7} \lambda_{t} \gamma_{a} \kappa_{I}
$$

As before, $\lambda_{t}$ takes a value of 1 if the observation is post announcement (or roll). $\gamma_{a}$ is 1 when the observation was added to an index and 0 if it is removed. $\kappa_{I}$ indicates which index the entity was added to or removed from and takes a value of 1 when the affected index is the HY index. $\beta_{7}$ in the above equation is the triple difference estimator-it is the difference in relative changes (inclusion relative to removal) in the CDS basis between entities that were added to the HY index versus the IG index. While there might be differences in behavioral response for entities that are added rather than removed, it is harder to come up with plausible explanations for there being significant difference for swaps added to the HY index rather than the IG since the only fundamental difference between the two indices is the credit rating of the firm. As credit rating is known publicly before the announcement, the difference in credit rating cannot explain why $\beta_{7} \neq 0$. Margin-based asset pricing, however, does predict that $\beta_{7} \neq 0$ precisely because the cash flows and tranching of the two indices are different. The result is reported in Table 3.

\section{B.4 Empirical Results}

As shown in table 1, we find that inclusion into an index is associated with an $18 \%$ increase in the CDS bond basis at the time of announcement while removal has no significant effects on the CDS bond basis around the announcement. There are no significant changes for either group around the time of the roll, which suggests that the market has already adjusted by the time of the roll. The lack of a significant coefficient on removal could be due to the fact that the "removed" sample is much smaller because many entities removed after experiencing a credit event.

To better compare included observations from excluded ones, we run a difference-in-difference regression comparing only included entities to excluded entities with results reported in Table $2 .{ }^{15}$ we find that the difference in the change of bases between these two groups is significant-addition relative to removal is associated with a $26 \%$ increase in the CDS-bond basis. This estimate matches

\footnotetext{
${ }^{15}$ To increase sample size, we also include "updated" entities. The entities included in the new roll are in the inclusion group while the entities that are phased out are in the exclusion group.
} 
Table 2: Difference in difference estimations comparing inclusion to exclusion. The last two specifications include controls for the month and year, as well as indicators for whether the entity switched indices. The month and year controls are not shown in the table.

\begin{tabular}{|c|c|c|c|c|}
\hline & \multicolumn{4}{|c|}{ Dependent variable: Normalized CDS basis (percent changes } \\
\hline & $\begin{array}{c}\text { announcement } \\
\text { (1) }\end{array}$ & $\begin{array}{l}\text { roll } \\
(2)\end{array}$ & $\begin{array}{c}\text { announcement } \\
\text { (3) }\end{array}$ & $\begin{array}{l}\text { roll } \\
(4)\end{array}$ \\
\hline time & $\begin{array}{l}-0.046 \\
(0.066)\end{array}$ & $\begin{array}{c}0.091 \\
(0.060)\end{array}$ & $\begin{array}{l}-0.046 \\
(0.066)\end{array}$ & $\begin{array}{c}0.091 \\
(0.060)\end{array}$ \\
\hline added & $\begin{array}{l}-0.000 \\
(0.066)\end{array}$ & $\begin{array}{l}-0.000 \\
(0.054)\end{array}$ & $\begin{array}{c}0.004 \\
(0.068)\end{array}$ & $\begin{array}{l}-0.030 \\
(0.055)\end{array}$ \\
\hline switch to HY & & & $\begin{array}{l}0.123^{*} \\
(0.070)\end{array}$ & $\begin{array}{c}0.038 \\
(0.075)\end{array}$ \\
\hline switch to IG & & & $\begin{array}{l}-0.021 \\
(0.089)\end{array}$ & $\begin{array}{l}-0.112 \\
(0.087)\end{array}$ \\
\hline time*added & $\begin{array}{c}0.259^{* * *} \\
(0.094)\end{array}$ & $\begin{array}{c}0.007 \\
(0.077)\end{array}$ & $\begin{array}{c}0.259^{* * *} \\
(0.093)\end{array}$ & $\begin{array}{c}0.007 \\
(0.077)\end{array}$ \\
\hline Observations & 214 & 486 & 214 & 486 \\
\hline $\mathrm{R}^{2}$ & 0.081 & 0.013 & 0.132 & 0.038 \\
\hline Adjusted $\mathrm{R}^{2}$ & 0.068 & 0.007 & 0.071 & 0.009 \\
\hline
\end{tabular}

the differences in the point estimates in Table 2.

\section{B.5 Alternative hypotheses}

It is possible that CDS contracts that are added to an index become more liquid as a result of inclusion, and the increase in the liquidity premium increases only the CDS spread and not the bond spread. Figure 2 and 3 show the trading volume of HY and IG CDS contracts with the roll dates highlighted. Trade volumes spike on the roll date of the index, but this increase in trade volume is temporary. There is no significant increase in trade volume around the time of the announcement. The result from the previous section finds that there is no significant change in the CDS-bond basis around the roll date, and this suggests that liquidity is not the driving force behind changes in bases. 
To eliminate confounding variables that arise from behavioral responses by market participants, we look at a triple difference estimation following Equation (9). The only difference between addition to the HY index and addition to the IG index is the credit rating of the firm, which is publicly known well before the announcement or roll dates. As such, if different market reactions to addition versus removal resulted in changes to the CDS-bond bases, such reactions should not be present in the triple-difference regression. Table 3 shows that the change in the CDS basis for added entities relative to removed entities is 41 percent higher when the entity was added to the HY index rather than the IG index. This result implies that the implicit margin for a CDS contract in the HY index is much lower than the margin for contracts in the IG index, likely because the HY index is composed of fewer entities, so that each individual entity accounts for a greater percentage of the index's cash flows.

\section{Three-State Model with Collateral and CDS}

This section presents a multi-state extension of Fostel and Geanakoplos (2012a) with the addition of tranching or pyramiding. The restriction to debt requires imposing more structure on preferences and endowments. In this environment, we are able to completely characterize equilibria, as well as derive similar results regarding how structured finance affects the basis. We first present the three-state model and then characterize equilibria with different financial regimes. Proofs are in Appendix C. 10 .

\section{C.1 The Model}

\section{Time, Assets, and Investors}

We consider a two-period, three-state model with time $t=0,1$. Uncertainty is represented by a tree $S=\{0, U, M, D\}$ with a root $s=0$ at $t=0$ and three states of nature $s=U, M, D$ at $t=1$. There are two fundamental assets, $X$ and $Y$, which produce dividends of the consumption good at time 1. Asset $X$ is risk-free, producing (as a normalization) 1 unit of the consumption good in every final state. Asset $Y$ is risky, producing $d_{U}^{Y}=1$ unit in state $U$ (a normalization), $d_{M}^{Y}<1$ units in state $M$, and $d_{D}^{Y}<d_{M}^{Y}$ in state $D$. We think of asset $Y$ as a financial asset, such as a corporate bond, a pool of 
Table 3: Triple-difference estimations comparing the effect of inclusion versus exclusion for the HY index relative to the IG index. The first two specifications looks at the percent change in the CDS-bond basis around the time of the announcement and roll. The last two specifications include controls for the month and year, as well as indicators for whether the entity switched indices. The month and year controls are not shown in the table.

\begin{tabular}{|c|c|c|c|c|}
\hline & \multicolumn{4}{|c|}{ Dependent variable: Normalized CDS basis (percent changes) } \\
\hline & $\begin{array}{c}\text { announcement } \\
\text { (1) }\end{array}$ & $\begin{array}{l}\text { roll } \\
(2)\end{array}$ & $\begin{array}{c}\text { announcement } \\
\text { (3) }\end{array}$ & $\begin{array}{l}\text { roll } \\
(4)\end{array}$ \\
\hline time & $\begin{array}{l}-0.046 \\
(0.091)\end{array}$ & $\begin{array}{l}0.221^{* * *} \\
(0.076)\end{array}$ & $\begin{array}{l}-0.046 \\
(0.091)\end{array}$ & $\begin{array}{c}0.221^{* * *} \\
(0.076)\end{array}$ \\
\hline added & $\begin{array}{c}0.000 \\
(0.092)\end{array}$ & $\begin{array}{l}-0.000 \\
(0.070)\end{array}$ & $\begin{array}{c}0.028 \\
(0.096)\end{array}$ & $\begin{array}{l}-0.011 \\
(0.071)\end{array}$ \\
\hline HY & $\begin{array}{c}0.000 \\
(0.090)\end{array}$ & $\begin{array}{c}0.000 \\
(0.084)\end{array}$ & $\begin{array}{c}0.022 \\
(0.099)\end{array}$ & $\begin{array}{c}0.027 \\
(0.086)\end{array}$ \\
\hline Switch to HY & & & $\begin{array}{c}0.084 \\
(0.077)\end{array}$ & $\begin{array}{c}0.048 \\
(0.076)\end{array}$ \\
\hline Switch to IG & & & $\begin{array}{l}-0.011 \\
(0.086)\end{array}$ & $\begin{array}{l}-0.099 \\
(0.085)\end{array}$ \\
\hline announced $\times \mathrm{HY}$ & $\begin{array}{l}0.0002 \\
(0.128)\end{array}$ & $\begin{array}{c}-0.317^{* * *} \\
(0.118)\end{array}$ & $\begin{array}{l}0.0002 \\
(0.128)\end{array}$ & $\begin{array}{c}-0.317^{* * *} \\
(0.118)\end{array}$ \\
\hline announced $\times$ added & $\begin{array}{c}0.038 \\
(0.130)\end{array}$ & $\begin{array}{c}0.009 \\
(0.099)\end{array}$ & $\begin{array}{c}0.038 \\
(0.130)\end{array}$ & $\begin{array}{c}0.009 \\
(0.099)\end{array}$ \\
\hline added $\times$ HY & $\begin{array}{l}-0.000 \\
(0.127)\end{array}$ & $\begin{array}{c}0.000 \\
(0.107)\end{array}$ & $\begin{array}{l}-0.028 \\
(0.141)\end{array}$ & $\begin{array}{l}-0.046 \\
(0.111)\end{array}$ \\
\hline announced $\times$ added $\times \mathrm{HY}$ & $\begin{array}{l}0.412^{* *} \\
(0.180)\end{array}$ & $\begin{array}{c}0.029 \\
(0.151)\end{array}$ & $\begin{array}{l}0.412^{* *} \\
(0.180)\end{array}$ & $\begin{array}{c}0.029 \\
(0.151)\end{array}$ \\
\hline Observations & 214 & 486 & 214 & 486 \\
\hline $\mathrm{R}^{2}$ & 0.166 & 0.078 & 0.209 & 0.102 \\
\hline Adjusted $\mathrm{R}^{2}$ & 0.138 & 0.064 & 0.136 & 0.067 \\
\hline
\end{tabular}


mortgages, or an asset-backed security, rather than a physical asset like a house or the assets of a firm. With a slight abuse of notation we let $M, D$ be the dividends in states $M, D$ with $D<M<1$. Asset payoffs are shown in Figure 5.

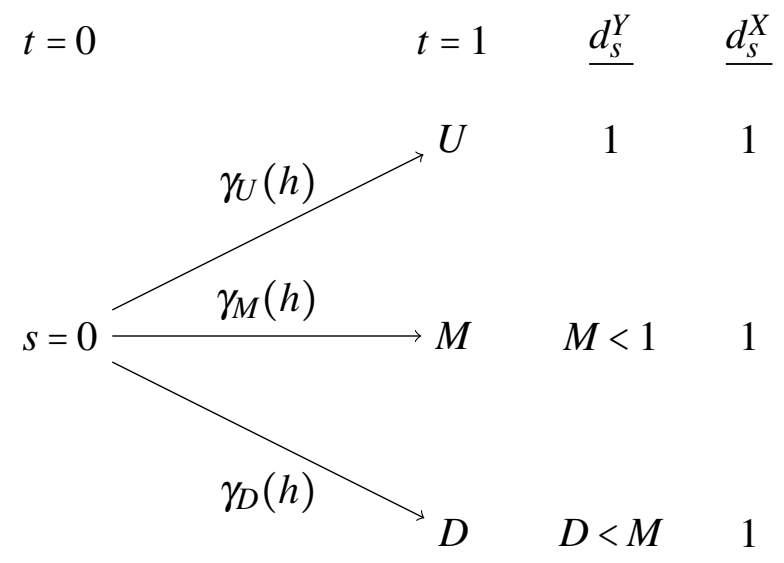

Figure 5: Payoff tree of assets $X$ and $Y$ in three-state world.

We suppose that agents are uniformly distributed on $(0,1)$, that is they are described by Lebesgue measure. (We will use the terms "agents" and "investors" interchangeably.) Agents are risk-neutral and have linear utility in consumption $c$ at time 1. Each agent $h \in(0,1)$ assigns subjective probability $\gamma_{s}(h)$ to the state $s$, and beliefs $\gamma_{s}(h)$ are continuous in $h$. The expected utility of agent $h$ is

$$
U^{h}(c)=\gamma_{U}(h) c_{U}+\gamma_{M}(h) c_{M}+\gamma_{D}(h) c_{D}
$$

where $c_{s}$ is the consumption in state $s$. At $t=0$, each investor is endowed with 1 unit of each asset $X$ and $Y$.

To ensure that in equilibrium investors' positions are sorted by their level of optimism, we suppose hazard rate dominance (see also Simsek, 2013; Gong and Phelan, 2019), which we can write as

$$
\gamma_{U}(h)+\gamma_{M}(h) \text { and } \frac{\gamma_{U}(h)}{\gamma_{U}(h)+\gamma_{M}(h)} \text { are increasing in } h
$$

High $h$ investors believe that state $D$ is unlikely and that, conditional on the state being at least $M$, state $U$ is relatively likely. This setup is equivalent to a model with finitely many heterogeneous risk-averse agents, where endowments and preferences are such that marginal utilities or "hedging 
needs" are monotonic and uniformly increasing by state.

\section{Financial Contracts and Collateral}

We restrict attention to debt contracts and CDS. Debt contracts, denoted $j_{\ell}$, promise non-contingent payments $(\ell, \ell, \ell)$. Without loss of generality, we suppose that all debt contracts are collateralized by one unit of the risky asset $Y$ (selling a non-contingent promise backed by $X$ as collateral would be equivalent to selling a fraction of $X$ ). Debt contracts with promises $\ell \leq D$ are fully collateralized (never default) and are therefore risk free. Debt contracts with $D<\ell \leq M$ will default in state $D$ but deliver the promise $\ell$ in states $U$ and $M$.

A CDS contract on the risky asset $Y$, denoted by $C D S_{Y}$, pays $1-d_{s}^{Y}$ in state $s$ (the difference between the maximum payout of $Y$ and the actual payout of $Y$ ). To simplify the analysis, we require that each unit of the CDS contract be fully collateralized so that any agent selling the $C D S_{Y}$ contract is able to repay his obligations regardless of which state is realized. ${ }^{16}$ The safe asset $X$ can serve as collateral for CDS. Since $C D S_{Y}$ pays $(0,1-M, 1-D)$, every unit of $C D S_{Y}$ must be collateralized by $(1-D)$ units of $X$. (Alternatively, an agent holding one unit of $X$ can sell $\frac{1}{1-D}$ units of $C D S_{Y}$.) When $Y$ can serve as collateral for CDS, one $C D S_{Y}$ contract must be backed by $\frac{D}{1-D}$ units of $Y$; alternatively, $\frac{1}{D}$ units of $Y$ can back $\frac{1}{1-D}$ units of $C D S_{Y}$. We let $J^{Y}$ and $J^{X}$ be the set of promises backed by $Y$ and $X$ respectively. Thus, to start $J^{X}=\left(C D S_{Y},(1-D) X\right)$. Later we will introduce a CDS on risky debt contracts (specifically on $j_{M}$ ), which will expand $J^{X}$.

Definition 4. Debt collateralization is the process by which agents use debt contracts $j \in J^{Y}$ to issue financial promises in the form of debt or CDS. An economy with debt collateralization is one in which agents are allowed to use any debt contract as collateral.

We allow agents to trade contracts of the form $j_{\ell}^{1}=\left(\ell, j_{M}\right)$. This contract promises a noncontingent payment $(\ell, \ell, \ell)$ backed by the risky debt $j_{M}$ acting as collateral. The restriction to $j_{M}$ is without loss of generality; we could let any contract $j \in J^{Y}$ serve as collateral, but in equilibrium

\footnotetext{
${ }^{16}$ This restriction is not without loss of generality for the equilibrium regime, though our main results continue to hold. As will be clear from the analysis that follows, if agents could sell "partially collateralized CDS," then in equilibrium some agents would sell CDS collateralized by only $1-M$ units of $X$, which would yield the CDS buyers a payoff of $(0,1-M, 1-M)$ and the sellers a payoff of $(1-M, 0,0)$. The first payoff would be attractive to "high pessimists" and the second payoff would be attractive to the most optimistic agents, and is equivalent to buying $Y$ and promising $M$, which we consider in the sections with leverage.
} 
only $j_{M}$ will be traded and thus only $j_{M}$ will serve as collateral (Gong and Phelan, 2019). The

contract $j_{M}$ delivers $d_{S}^{j_{M}}=(M, M, D)$, and the payoff to $j_{\ell}^{1}$ in each state is $\min \left\{\ell, d_{S}^{j_{M}}\right\}$. Note that the act of holding $j_{M}$ and selling the contract $j_{D}^{1}$ is equivalent to buying $j_{M}$ with leverage promising $D$, yielding a payoff of $(M-D, M-D, 0)$. We also allow agents to use safe debt $j_{D}$ to issue CDS, which is the contract $\left(C D S_{Y},(1-D) j_{D}\right)$, and this contract has identical payoffs to CDS backed by $X$. Denote the set of contracts backed by $j_{M}$ and $j_{D}$ by $J^{1}$.

In our model, variations in the financial environment are the drivers of variations in CDS bases. These variations can reflect changes in how assets or contracts are used as collateral or changes in how assets are tranched in securitized markets. Before proceeding with the theoretical analysis, we explain this equivalence in greater detail. To fix ideas, let $M=0.3$ and $D=0.1$.

Consider when debt contracts can be used as collateral, and consider the following equilibrium regime. Some investors buy the risky asset $Y$ with maximum leverage, issuing a risky debt contract that promises $M=0.3$. This debt contract will default in state $D$, and thus the payoff is $(0.3,0.3,0.1)$. The investors that bought $Y$ and issued the contract would be left with payoffs $(0.7,0,0)$. Another set of investors would buy this risky debt with leverage, issuing a risk-free debt contract that promises $D=0.1$. The investors in risky debt would be left with payoffs $(0.2,0.2,0)$.

In total, investors in the economy will hold the following set of payoffs, $(0.7,0,0) ;(0.2,0.2,0)$; $(0.1,0.1,0.1)$, all of which are ultimately backed by the payoffs to $Y$. These payoffs are exactly what would occur if $Y$ were tranched into senior-subordinated tranches. The most senior tranche would be guaranteed to pay in every state, and thus could deliver $D=0.1$. The mezzanine tranche would default in state $D$ but would otherwise be able to deliver 0.2. The subordinated, or equity, tranche would deliver the residual payment in state $U$ alone, delivering 0.7 .

\section{C.2 Baseline Results}

Note that the payout of holding one unit of $X$ is equivalent to holding one unit of $Y$ and one unit of $C D S_{Y}$. Thus, the basis can be equivalently defined to be the difference in the price of these two options: $\operatorname{Basis}_{Y}=\left(p+\pi_{C}^{Y}\right)-1$, or $p+\pi_{C}^{Y}=1+\operatorname{Basis}_{Y}$. We use the term "cash-synthetic asset" to refer to a portfolio consisting of equal units of $Y$ and $C D S_{Y}$ since this option, like $X$, is completely risk-free. 
We first characterize the basis in an economy without short selling. We consider when agents can (1) use $X$ as collateral to issue $C D S_{Y}$; (2) use $Y$ as collateral to issue debt contracts and to issue $C D S_{Y}$; and (3) use debt contracts to issue debt and $C D S_{Y}$. We refer to (2) as the leverage economy $^{17}$ and (3) as the debt-collateralization (or structured finance) economy. This section presents the main theoretical results, and later sections provide the complete characterizations of equilibria.

Limiting leverage (i.e., restricting the set of contracts backed by $Y$ ) decreases the basis. If $Y$ is imperfect collateral, perhaps due to regulations or because financial markets have concerns arising from informational frictions, then the basis will be negative. If the risky asset $Y$ can be used as collateral to issue debt contracts and $C D S_{Y}$, then the basis is nonnegative. The following proposition extends the results in Fostel and Geanakoplos (2012a) to multi-state economies.

Proposition 4. Suppose that the only financial contracts agents can trade are debt and a CDS on Y. Then,

1. (No leverage) If only $X$ can serve as collateral for financial contracts, then agents will issue $C D S_{Y}$ backed by $X$ and the basis on $Y$ is negative, $\pi_{C}^{Y}+p<1$.

2. (Leverage) If $X$ and $Y$ can serve as collateral for financial contracts, then in the following cases

(a) if there are limits on the collateral ability of $Y$ so that $Y$ cannot issue $C D S_{Y}$ and $Y$ can only issue safe debt, then the basis is negative $p+\pi_{C}^{Y}<1$.

(b) if there are no limits on the collateral ability of $Y\left(Y\right.$ can issue $C D S_{Y}$ and any kind of debt), then the basis is non-negative $\pi_{C}^{Y}+p \geq 1$.

3. (Debt Collateralization) If $X, Y$, and debt can serve as collateral for financial contracts, then the basis is positive $\pi_{C}^{Y}+p>1$.

Here is the intuition for the results. The price of an asset can be decomposed into the sum of its "payoff value" (PV) and its "collateral value" (CV) to any agent who holds the asset. The PV is an agent's normalized expected marginal utility of the future dividends; the CV measures

\footnotetext{
${ }^{17}$ This case has been considered by Fostel and Geanakoplos (2012a) in a two-state economy.
} 
the asset's value of the collateral capacity of the asset, which is also how much the agent values liquidity. ${ }^{18}$ When an asset can be used as collateral, its price generally exceeds the payoff value. When an asset cannot act as collateral, the $\mathrm{CV}$ is always zero. When the risky asset $Y$ cannot be used as collateral at all (case 1) or for CDS (case 2), then $X$ is superior collateral and then $Y$ trades at a negative basis to $X$. When $Y$ can be used as collateral without constraint, then $X$ does not have greater collateral capacity and so the basis disappears. Indeed, since CDS must be fully collateralized whereas $Y$ could be used to issue risky debt (which might default), $X$ has a limited collateral capacity compared to $Y$ and so $Y$ may trade at a premium.

Finally, with structured finance as in the third case, debt backed by $Y$ can be used as collateral. This increases the collateral value of $j_{M}$ (since agents buying $j_{M}$ have the ability to sell $j_{D}^{1}$ ), increasing $\pi^{M}$ in equilibrium. Since agents can leverage their purchases of $Y$ by borrowing $\pi^{M}$, agents can now buy $Y$ with higher leverage, raising the equilibrium demand for $Y$. Debt collateralization increases the collateral value of $Y$ because $Y$ can be used to issue $j_{M}$ and therefore inherits some of the increase in the collateral value of $j_{M}$. Thus the risky asset $Y$ now has two "levels" of collateralization - the first from allowing $Y$ to back debt contracts, and the second from allowing these debt contracts to back further contracts. The collateral value of $X$ does not change because it can still issue only one contract, $C D S_{Y}$. In other words, $Y$ back all the same contracts that $X$ can, but $Y$ can also back contracts that can be further collateralized downstream. ${ }^{19}$ These forces increase the price of $Y$ relative to the price of $X$ and result in a positive basis.

\section{C.3 No Leverage: $C^{j}=X$}

We first characterize equilibrium with no leverage before considering when $Y$ can serve as collateral.

Consider the scenario in which agents cannot use $Y$ as collateral to issue debt contracts. Formally, $J^{Y}=\varnothing$ and $J=J^{X}=\left(C D S_{Y},(1-D) X\right)$ is the only financial contract available for trade. We denote the act of holding $X$ and selling the maximum allowable amount of $C D S_{Y}$ by $X / C D S_{Y}$. In this regime, agents can take any of the following positions: (i) $X / C D S_{Y}$ (hold $X$ and sell $C D S_{Y}$ ),

\footnotetext{
${ }^{18}$ Fostel and Geanakoplos (2008) define the PV of an asset $j$ to an agent $i$ as $P V_{j}^{i} \equiv \sum_{s \in S} \gamma_{s}^{i} d_{s}^{j}\left(\frac{d u^{i}\left(c_{s}^{i}\right)}{d c}\right) /\left(\frac{d u^{i}\left(c_{0}^{i}\right)}{d c}\right)$, where $u^{i}$ is the utility of agent $i$ and $\gamma_{s}^{i}$ is the subjective probability the agent assigns to state $s$.

${ }^{19}$ Agents have no desire to use $X$ to issue debt contracts since leveraging a completely safe asset provides no benefits
} 
(ii) buy $Y$, (iii) buy $X$ or the cash-synthetic asset made of a portfolio of both $Y$ and $C D S_{Y}$, and (iv) buy the financial contract $C D S_{Y}$. Notice that the above positions are listed in terms of decreasing optimism/increasing pessimism. An agent who believes that state $U$ is very likely to happen will choose to either buy $Y$ or hold $X / C D S_{Y}$, whereas an agent who believes that state $D$ is more likely will want to purchase $C D S_{Y}$. Because agents are risk neutral, every agent will choose exactly one of the above positions based on how optimistic they are. The following result characterizes equilibrium in this economy.

Lemma 3. In this regime, no agent chooses to hold safe assets without selling financial contracts. That is, no agent chooses to hold simply $X$ or the cash-synthetic asset made of a portfolio of $Y$ and $C D S_{Y}$. In fact, any agent who holds $X$ will also sell the maximum allowable amount of $C D S_{Y}$.

The intuition is straightforward. Any agent who does not want to buy $X$ and sell the CDS must value consumption in state $D$. This is because selling the CDS means that the agent loses consumption if the down state occurs. Thus, these agents are relatively pessimistic (compared to agents who do choose to sell the CDS) and must therefore be willing to sacrifice consumption in state $U$ for the chance to have even more consumption in state $M$ or $D$. Since $C D S_{Y}$ pays $(0,1-M, 1-D)$, in equilibrium prices must be such an agent will want to invest in $C D S_{Y}$ rather than hold $X$. The basis must be negative in this economy (Proposition 4).

In this equilibrium regime, agents choose to hold $X$ rather than the cash-synthetic asset even though the two have equivalent payoffs and the latter is cheaper. While this outcome may seem illogical, the result occurs in equilibrium because neither $Y$ nor $C D S_{Y}$ can be used as collateral: neither have collateral value. Thus, agents hold $X$ precisely because it allows them to sell the CDS, and therefore isolate payoffs in states $U$ and $M$. Any agent who chooses to hold the portfolio of $Y$ and $C D S_{Y}$ cannot isolate payoffs in any states but accepts equal payoffs in every state. It is worth contrasting this result with traditional theories that ignore collateral. Traditional theory predicts that the CDS spread should be equal to the bond spread, due to the arbitrage opportunity that would arise otherwise. Even when agents cannot short-sell assets, the spreads should still be equal because agents can always choose buy the cheaper option-either the safe asset or a combination of the risky asset and its CDS. It is the ability of $X$ to issue financial contracts that gives $X$ a higher price. Combining these results, we obtain the following lemma, which describes equilibrium in 
this regime.

Lemma 4. In this economy, equilibrium consists of the following portfolio positions, ordered by investors: (1) $X / C D S_{Y}$, (2) $Y$, and (3) $C D S_{Y}$.

There are two marginal buyers $h_{1}$ and $h_{2}$. The most optimistic agents in the economy $h>h_{1}$ will sell their endowment of $Y$ to buy $X$ and issue the maximum allowable number of $C D S_{Y}$. Moderate agents $h \in\left(h_{1}, h_{2}\right)$ will sell their endowment of $X$ to buy all the units of the risky asset $Y$. Pessimists $h<h_{2}$ will sell their endowment of $X$ and $Y$ to buy the financial contract $C D S_{Y}$ sold by optimists. Figure 6 illustrates the equilibrium regime. Arrows point from lender to borrower and we see pessimists (those holding $C D S_{Y}$ ) lending to optimists (those holding $X / C D S_{Y}$ ) in this economy.

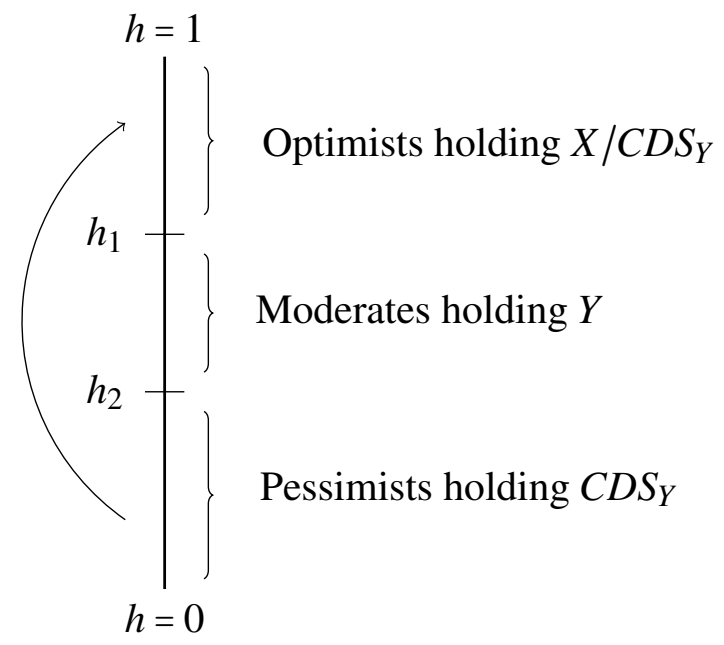

Figure 6: Equilibrium with $C D S_{Y}$, no leverage. Holders of $C D S_{Y}$ fund optimists.

Marginal investors are indifferent between two different options. Agent $h_{1}$ is indifferent between selling the $C D S_{Y}$ collateralized by $X$ and buying the risky asset $Y$

$$
\frac{\gamma_{U}\left(h_{1}\right)(1-D)+\gamma_{M}\left(h_{1}\right)(M-D)}{1-D-\pi_{C}^{Y}}=\frac{\gamma_{U}\left(h_{1}\right)+\gamma_{M}\left(h_{1}\right) M+\gamma_{D}(h) D}{p}
$$

Agent $h_{2}$ is indifferent between buying $Y$ and buying the financial contract $C D S_{Y}$

$$
\frac{\gamma_{U}\left(h_{2}\right)+\gamma_{M}\left(h_{2}\right) M+\gamma_{D}(h) D}{p}=\frac{\gamma_{M}\left(h_{2}\right)(1-M)+\gamma_{D}\left(h_{2}\right)(1-D)}{\pi_{C}^{Y}} .
$$


Market clearing for $X$ requires

$$
\frac{\left(1-h_{1}\right)(1+p)}{1-\frac{\pi_{C}^{Y}}{1-D}}=1
$$

and market clearing for $Y$ requires

$$
\frac{\left(h_{1}-h_{2}\right)(1+p)}{p}=1
$$

Equation (12) states that agents buying $X, h \in\left(h_{1}, 1\right)$ will spend all of their endowment, $(1+p)$ to purchase $X$, which has price 1 . With each unit of $X$ they buy, they will also sell $\frac{1}{1-D}$ units of $C D S_{Y}$, which has price $\pi_{C}^{Y}$. The revenue from these sales is used to buy more $X$. The demand for $X$ is equal to the supply, which is 1 . Equation (13) states that agents buying the risky asset $Y, h \in\left(h_{2}, h_{1}\right)$ will spend all of their endowment on $Y$, which has price $p$, and that the amount demanded by these agents must be equal to the unit supply in the economy.

\section{C.4 Leverage Economy: $C^{j} \in\{X, Y\}$}

Consider when the risky asset $Y$ can be used as collateral to issue debt contracts and $C D S_{Y}$. In particular, one unit of $Y$ can back a non-contingent debt promise $(\ell, \ell, \ell)$, or $\frac{1-D}{D}$ units of $Y$ can back one (fully collateralized) CDS contract. This is due to the fact that the CDS pays $1-D$ in the same state when $Y$ pays $D$.

The results of Fostel and Geanakoplos (2012a,b) characterize which contracts will be traded in equilibrium in an economy with only debt contracts, and these results allow us to characterize equilibrium with $C D S$. In an economy with debt contracts and without leverage limits, two debt contracts are traded in equilibrium: $j_{D}=D$ and $j_{M}=M$, with prices $\pi^{D}$ and $\pi^{M}$ respectively. The contract $j_{D}$ delivers $(D, D, D)$, while $j_{M}$ delivers $(M, M, D)$. Unlike the safe promise $j_{D}$, the delivery of $j_{M}$ depends on the realization of the state at time 1 . Therefore, $j_{M}$ is risky and has price $\pi^{M}<M$. The interest rate for $j_{M}$ is strictly positive and is given by $i_{M}=\frac{M}{\pi^{M}}-1$, and is endogenously determined in equilibrium.

First, note that holding 1-D units of $Y$ and selling $D$ units of CDS contracts yields $(1-D, M-$ $D, 0)$, which is the same payoff as holding one unit of $Y$ and selling the promise $j_{D}$. Second, holding $(1-D)$ of $X$ and selling one unit of $C D S_{Y}$ also yields the same payoff as holding one 
unit of $Y$ and selling the promise $j_{D}$. We denote buying $Y$ and selling CDS by $Y / C D S_{Y}$, buying $Y$ and selling $j_{D}$ by $Y / j_{D}$, and buying $X$ and selling $\operatorname{CDS}$ by $X / C D S_{Y}$, where all positions are appropriately scaled to be fully collateralized: $Y / C D S_{Y} \operatorname{costs}(1-D) p-D \pi_{C}^{Y} ; Y / j_{D} \operatorname{costs} p-\pi^{D}$; $X / C D S_{Y}$ costs $1-D-\pi_{C}^{Y}$. Since all positions yield the same cash flows, investors will choose the positions which are cheapest. An immediate implication is that the equilibrium basis is nonnegative.

If the basis were negative, then agents would prefer to use $Y$ as collateral to issue CDS over using $X$, and so no agent would hold $X$. In fact, we can say more: if the basis is zero, then $X / C D S_{Y}$ is equivalent to $Y / C D S_{Y}$ and both will be traded in equilibrium; when the basis is strictly positive then $X / C D S_{Y}$ is cheaper and no agent will trade $Y / C D S_{Y}$ in equilibrium. Accordingly, equilibrium in the leverage economy can be described by three marginal investors $h_{1}, h_{2}, h_{3}$. Investors $h>h_{1}$ buy the risky asset $Y$ and issue risky debt. Investors with $h \in\left(h_{2}, h_{1}\right)$ issue CDS contracts, using either $X$ or $Y$ as collateral. Investors with $h \in\left(h_{3}, h_{2}\right)$ buy risky debt, and the remaining investors buy CDS.

Lemma 5. In the leverage economy, equilibrium consists of the following portfolio positions, ordered by investors: (1) $Y / j_{M}$, (2) $X / C D S_{Y} \equiv Y / C D S_{Y}$, (3) $j_{M}$, (4) and $C D S_{Y}$. When the basis is zero, then a fraction of $Y$ is used for $Y / C D S_{Y}$, but no agents trade $Y / C D S_{Y}$ when the basis is positive.

That the four positions exist in equilibrium is immediate. Figure 7 shows the equilibrium regime. Arrows point from lender to borrower. In this economy, pessimists lend to optimists.

With leverage, equilibrium consists of three marginal investors, $h_{1}, h_{2}$, and $h_{3}$ and the following equations defining the marginal investors. Agent $h_{1}$ is indifferent between holding the risky asset with leverage promising $M$ and buying the risky asset with leverage promising $D$,

$$
\frac{\gamma_{U}\left(h_{1}\right)(1-M)}{p-\pi^{M}}=\frac{\gamma_{U}\left(h_{1}\right)(1-D)+\gamma_{M}\left(h_{1}\right)(M-D)}{p-D} .
$$

Agent $h_{2}$ is indifferent between buying the safe asset to sell $C D S_{Y}$ and holding the risky debt promising $M$

$$
\frac{\gamma_{U}\left(h_{2}\right)(1-D)+\gamma_{M}\left(h_{2}\right)(M-D)}{1-D-\pi_{C}^{Y}}=\frac{\left(\gamma_{U}\left(h_{2}\right)+\gamma_{M}\left(h_{2}\right)\right)(M)+\gamma_{D}\left(h_{2}\right) D}{\pi^{M}} .
$$




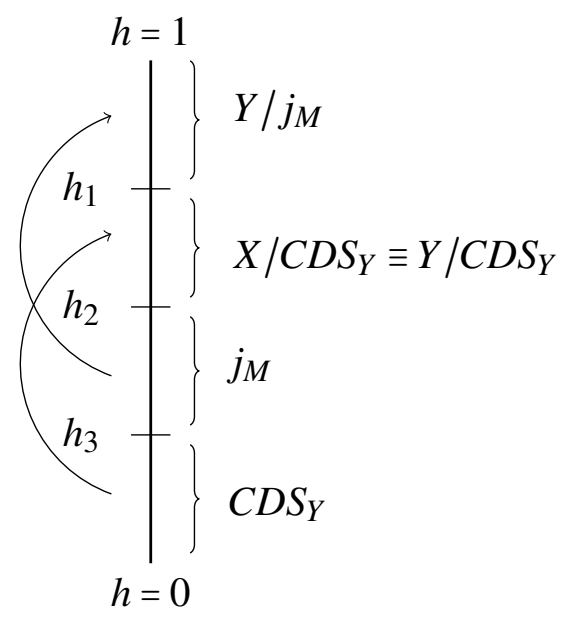

Figure 7: Equilibrium with leverage and $C D S_{Y}$ backed by $X$. Buyers of $C D S_{Y}$ fund moderates holding $X / C D S_{Y}$. Agents purchasing $j_{M}$ lend to optimists.

Agent $h_{3}$ is indifferent between holding the risky debt $j_{M}$ and buying the $C D S_{Y}$ contract.

$$
\frac{\left(\gamma_{U}\left(h_{3}\right)+\gamma_{M}\left(h_{3}\right)\right) M+\gamma_{D}\left(h_{3}\right) D}{\pi^{M}}=\frac{\gamma_{M}\left(h_{3}\right)(1-M)+\gamma_{D}\left(h_{3}\right)(1-D)}{\pi_{C}^{Y}} .
$$

Denote by $\eta$ the fraction of $Y$ used to back $C D S_{Y}$. Market clearing for the risky asset $Y$ requires

$$
\frac{\left(1-h_{1}\right)(1+p)}{p-\pi^{M}}=1-\eta
$$

Market clearing for risky debt $j_{M}$ requires

$$
\frac{\left(h_{2}-h_{3}\right)(1+p)}{\pi^{M}}=\frac{\left(1-h_{1}\right)(1+p)}{\left(p-\pi^{M}\right)} .
$$

The market clearing condition for $C D S_{Y}$ is

$$
\frac{h_{3}(1+p)}{\pi_{C}^{Y}}=(1+\eta D)\left(\frac{1}{1-D}\right) .
$$

Equation (17) states that the amount of risky asset $Y$ demanded by agents $h \in\left(h_{1}, 1\right)$ is equal to the amount of risky assets not backing $C D S_{Y}$. Equation (18) states that agents $h \in\left(h_{3}, h_{2}\right)$ will sell their endowment which has value $1+p$ and buy the risky debt, costing $\pi^{M}$ for each unit; this demand must equal the amount supplied, which is created by the agents $h \in\left(h_{1}, 1\right)$ who sell one unit of 
$j_{M}$ for every unit of $Y$ they hold. Finally, Equation (19) states that agents $h \in\left(0, h_{3}\right)$ will sell their endowment to buy $C D S_{Y}$, which has price $\pi_{C}^{Y}$ and that this demand is equal to the amount supplied in the economy - a total of $\frac{1}{(1-D)}$ units of $C D S_{Y}$ are created from the one unit of $X$ and $\frac{D}{1-D}$ units are created from the equilibrium amount $\eta$ backed by $Y$.

Notice that we could implement this equilibrium if we let any safe asset-specifically, $j_{D}$ in addition to $X$ - be used as collateral to back $C D S_{Y}$. Whether or not $Y$ can back $C D S_{Y}$, equilibrium would be unchanged. In equilibrium, if the basis is zero, then agents will trade $Y / j_{D}$, and every agent that buys $j_{D}$ will use it as collateral to sell $C D S_{Y}$ (just as they do with $X$ ). Thus, $\pi^{D}=D$, and the following positions will be equivalent: $X / C D S_{Y}, Y / j_{D}, j_{D} / C D S_{Y}$. The risky asset $Y$ would implicitly back $C D S_{Y}$ because it would be used to back safe debt which was used to back $C D S_{Y}$.

\section{C.4.1 Leverage Constraints and Negative Bases}

Before investigating how leverage limits affect the basis, we document that for almost all parameters, the basis is zero with full leverage. (Our theoretical result is simply that the basis is non-zero.) Figure 8 plots the basis in leverage economies, with beliefs parametrized by the form $\gamma_{U}(h)=h^{\zeta}$ and $\gamma_{M}(h)=h^{\zeta}\left(1-h^{\zeta}\right)$, when beliefs are given by $\zeta=0.5$ and $\zeta=1$. The parameter $\zeta$ determines the relative frequency of optimists and pessimists in the economy; equivalently, the frequency of pessimists can be interpreted as the relative demand for assets that pay in bad states (negativebeta assets), perhaps from hedging needs or risk aversion. High $\zeta$ corresponds to relatively more pessimists and low $\zeta$ to more optimists (with $\zeta>1, \gamma$ 's are convex; $\zeta<1$, concave).

In general the basis is zero, but as noted earlier the basis can be positive. In these cases, the risky asset $Y$ is not used to issue CDS but is exclusively used to issue risky debt. There is a small range with a positive basis around $M=0.3, D=0.08$. This region grows slightly as $\zeta$ decreases, but for $\zeta$ sufficiently high (for example, $\zeta=1.5$ ) the basis is always zero for all payoffs.

The zero-basis result emerges when $Y$ and $X$ have equal abilities to serve as collateral, albeit to make different promises. However, if $Y$ is imperfect collateral, perhaps because of regulations or because financial markets have concerns arising from informational issues, then the basis will be negative. This follows because if the collateral value of $Y$ decreases, then a negative basis emerges. Suppose that $Y$ can be used to issue debt contracts, but the maximum promise is $\bar{\ell}<M$. That is, one unit of $Y$ can at most back a non-contingent promise $(\bar{\ell}, \bar{\ell}, \bar{\ell})$. Furthermore, $Y$ cannot be used 


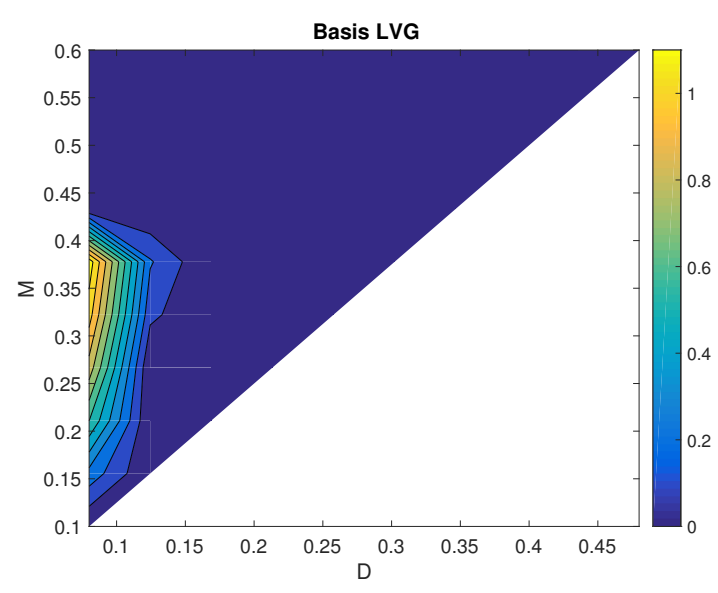

(a) Leverage: $\zeta=0.5$

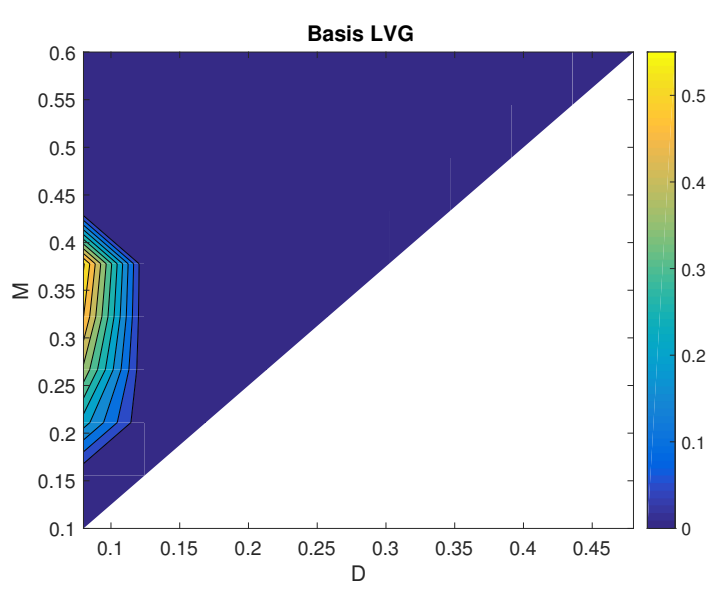

(b) Leverage: $\zeta=1$

Figure 8: Comparative Statics: basis (times 100) varying payoffs $M, D$ with leverage.

to issue $C D S$.

When $\bar{\ell} \leq D$, the only debt contract traded is $j_{\bar{\ell}}=\bar{\ell}$ which delivers the promised amount in every state of the world. However, because this safe debt cannot be used to issue $C D S$, it trades at a discount to $X$ (there is a basis on the safe debt), and so $\pi^{\bar{\ell}}<\bar{\ell}$. Equilibrium in this case is ordered as follows (starting with the most optimistic): agents holding $X$ to issue $C D S$; agents holding $Y$ and issuing safe debt (the leverage constraint); agents holding safe debt; agents holding $C D S$. Furthermore, the basis is negative. While we have not been able to prove so, numerical examples suggest that the basis is monotonic in $\bar{\ell}$ for $\bar{\ell}<D$, with the basis more negative the tighter is the leverage constraint (lower $\bar{\ell}$ ).

When $D<\bar{\ell}<M$, two debt contracts are potentially traded: the safe contract $j_{D}=D$ and a risky contract $j_{\bar{\ell}}=\bar{\ell}$. The $j_{D}$ contract delivers $(D, D, D)$ while the $j_{\bar{\ell}}$ contract delivers $(\bar{\ell}, \bar{\ell}, D)$ because agents default in the down state. Depending on parameters, in equilibrium agents may trade the risky contract only. While we have not been able to prove so in this case, numerical results (below) suggest that in either case the leverage constraint decreases the basis.

Figure 9 plots the basis with beliefs parametrized by the form $\gamma_{U}(h)=h^{\zeta}$ and $\gamma_{M}(h)=h^{\zeta}(1-$ $h^{\zeta}$ ), with $D=0.1$ and $M=0.3$, solving for the basis as a function of $\bar{\ell}$ and varying the parameter $\zeta$.

The numerical examples provide two results in addition to our propositions. First, for low $\zeta$ (corresponding to high levels of optimism or high marginal utilities in good states), the basis with leverage limits and when $Y$ cannot be used to issue $C D S$ converges to the basis without leverage 


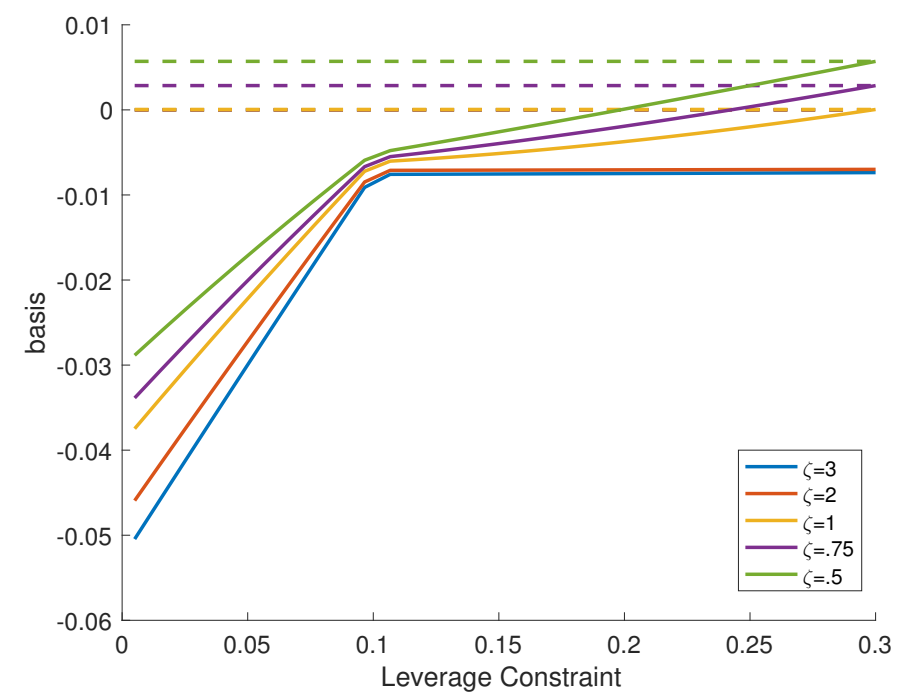

Figure 9: Leverage Constraints and the Basis. Dashed lines are the basis in an economy without leverage constraints and in which $Y$ can be used to issue $C D S$.

limits and when $Y$ can be used to issue $C D S$. In particular, in these cases the restriction that $Y$ cannot issue $C D S$ is not binding when leverage limits are relaxed (note that the basis would actually be positive in this case). In these economies, when $\bar{\ell}>D$ agents trade only risky debt in equilibrium.

However, when $\zeta$ is high (corresponding to low levels of optimism or high marginal utilities in bad states), the basis with leverage limits does not converge to the basis when $Y$ can be used to issue $C D S$. In these cases, in equilibrium agents use $Y$ to issue safe debt, and the basis on the asset exactly equals the basis on the safe debt .

Second, when neither safe assets nor $Y$ can back CDS contracts, the basis need not be monotonic in $\bar{\ell}$ when $D<\bar{\ell}<M$. In particular, when the economy features a relatively high demand for risk ( $\zeta$ is low, marginal utilities are high for higher states), the basis is monotonic. However, when the economy features a substantially high demand for negative-beta assets $(\zeta$ is high, marginal utilities are high for low states), the basis can decrease as $\bar{\ell}$ increases from $D$ to $M$. Varying the asset payoffs emphasizes these non-monotonicity results. Figure 10 plots the effects of leverage constraints on the basis, varying $\zeta$, for two different sets of payoffs. When in equilibrium agents do not use $Y$ to issue safe debt, the basis decreases significantly when $\bar{\ell}$ increases beyond $D$. In panel (a) to the left, for $\zeta=2,3$ agents use $Y$ to exclusively issue risky debt. In this case, increasing the 
leverage limit actually decreases the basis. However, when agents use $Y$ to issue safe debt, there is a basis on safe debt (because it cannot be used to issue $C D S$ while $X$ can), and the basis on the asset exactly equals the basis on the safe debt. Panel (b) to the right shows this for $\zeta=0.75,1,2$, and for $\bar{\ell}>.3$ for $\zeta=2.5$. For $\zeta=2.5$ the equilibrium regime shifts as leverage constraints rise. For the loosest constraints, agents use $Y$ to issue safe debt, but this is not the case for tighter constraints.

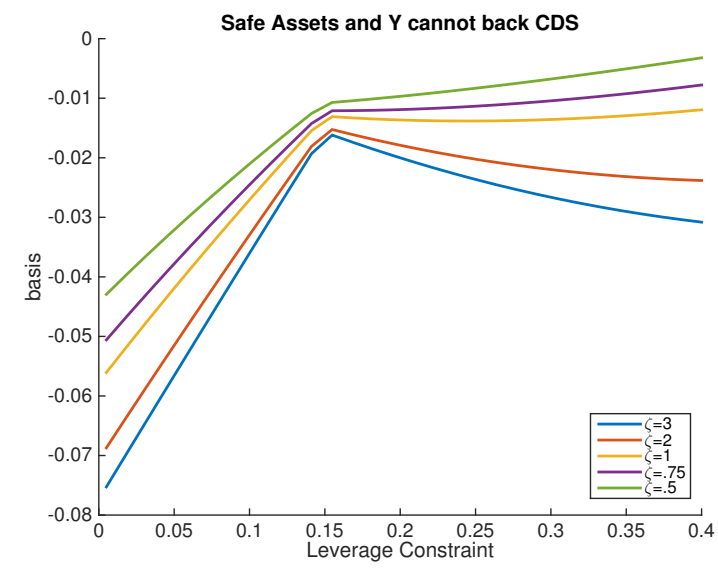

(a) $M=0.4, D=0.15$

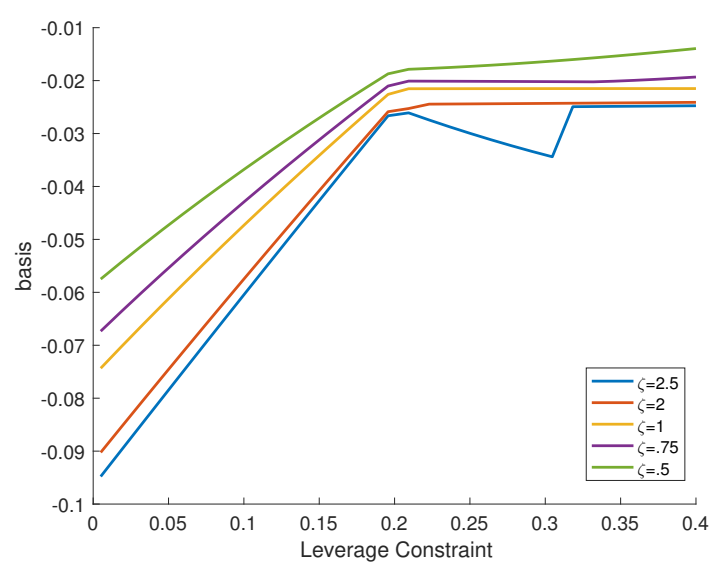

(b) $M=0.4, D=0.2$

Figure 10: Leverage Constraints and the Basis.

\section{C.5 Structured Finance (Pyramiding, Tranching) Economy: $C^{j} \in\left\{X, Y, j_{M}\right\}$}

Given our earlier results, we can proceed to characterize equilibrium.

Corollary 4. In the economy with debt collateralization and $C D S_{Y}$ backed by $X$, it is cheaper to hold $X / C D S_{Y}$ than $Y / j_{D}$. Thus, no agent will hold $Y / j_{D}$. That is, $(1-D)-\pi_{C}^{Y}<p-D$.

Lemma 6. In this economy, equilibrium consists of the following portfolio positions, ordered by investors: (1) $Y / j_{M}$, (2) $X / C D S_{Y} \equiv j_{D}^{1} / C D S_{Y}$, (3) $j_{M} / j_{D}^{1}$, and (4) $C D S_{Y}$. This characterization of equilibrium is not dependent on which assets can be used to issue $C D S_{Y}$. In fact, the equilibrium regime does not change even if we allow agents to use $Y$ and $j_{M}$ to back the CDS,

It is clear from earlier results that the above four positions must exist in equilibrium. Figure 11 depicts the equilibrium regime. There are three marginal buyers. Arrows demonstrate the lender-borrower relationship in this economy, pointing from lenders to borrowers. Compared to 
the leverage economy, there is no longer a clean lending relationship, with pessimistic investors always lending to more optimistic agents. In addition to the usual lending flows, in this equilibrium we also see relatively optimistic agents (those holding the safe asset and selling CDS) lending to more pessimistic agents (those holding the risky debt contract) by buying the safe debt contract issued by the pessimists. This occurs because the safe debt issued by these pessimists can be leveraged to make an even more optimistic trade. (This is a form of financial entanglement.)

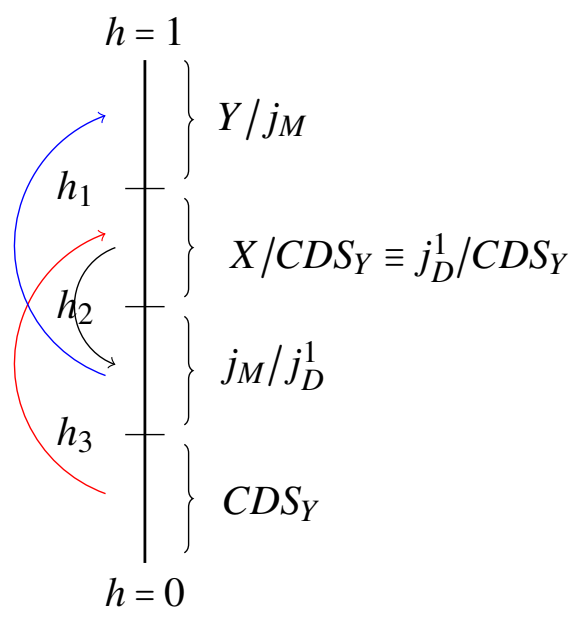

Figure 11: Equilibrium with debt collateralization and $C D S_{Y}$ backed by $X$. Regime features financial entanglement.

The following equations define marginal investors (given by equalizing expected returns on two investment options) in the debt collateralization economy. Agent $h_{1}$ is indifferent between buying $Y$ with leverage promising $M$ and holding $X$ while selling $C D S_{Y}$

$$
\frac{\gamma_{U}\left(h_{1}\right)(1-M)}{p-\pi^{M}}=\frac{\gamma_{U}\left(h_{1}\right)(1-D)+\gamma_{M}\left(h_{1}\right)(M-D)}{1-D-\pi_{C}^{Y}} .
$$

Agent $h_{2}$ is indifferent between buying $X$ to sell $C D S_{Y}$ and buying $j_{M}$ with leverage $D$

$$
\frac{\gamma_{U}\left(h_{2}\right)(1-D)+\gamma_{M}\left(h_{2}\right)(M-D)}{1-D-\pi_{C}^{Y}}=\frac{\left(\gamma_{U}\left(h_{2}\right)+\gamma_{M}\left(h_{2}\right)\right)(M-D)}{\pi^{M}-D}
$$

Agent $h_{3}$ is indifferent between buying the risky debt with leverage promising $D$ and buying the CDS

$$
\frac{\left(\gamma_{U}\left(h_{3}\right)+\gamma_{M}\left(h_{3}\right)\right)(M-D)}{\pi^{M}-D}=\frac{\gamma_{M}\left(h_{3}\right)(1-M)+\gamma_{D}\left(h_{3}\right)(1-D)}{\pi_{C}^{Y}}
$$


Market clearing for the safe asset $X$ requires

$$
\frac{\left(h_{1}-h_{2}\right)(1+p)}{1-\frac{\pi_{C}^{Y}}{1-D}}=1 .
$$

Market clearing for the risky debt $j_{M}$ implies that

$$
\frac{\left(h_{2}-h_{3}\right)(1+p)}{\pi^{M}-D}=1
$$

Finally, market clearing for $C D S_{Y}$ requires

$$
\frac{h_{3}(1+p)}{\pi_{C}^{Y}}=\frac{1}{1-D} .
$$

\section{C.5.1 Numerical Example}

While our results hold across parameters and are not quantitative, a numerical example is helpful to fix ideas. We let beliefs be $\gamma_{U}(h)=h, \gamma_{M}(h)=h(1-h)$, and let payoffs be $d_{M}^{Y}=0.3$ and $d_{D}^{Y}=0.1$. Table 4 compares equilibrium with no leverage, leverage, and debt collateralization. When debt backed by $Y$ can be used to back further debt contracts, the basis is positive since $Y$ now has two levels of collateralization. Our results explicitly demonstrate that the basis does not only depend on whether $Y$ can be used as collateral-it is also intrinsically linked to the collateral value of “downstream" promises backed by $Y$.

Table 4: Equilibrium with No Leverage, Leverage, and Debt Collateralization

\begin{tabular}{c|c|c|c} 
& No Leverage & Leverage & Debt Collateralization \\
\hline$p$ & 0.447 & $0.508 \uparrow$ & $0.529 \uparrow$ \\
$\pi_{C}^{Y}$ & 0.513 & $0.492 \downarrow$ & $0.491 \downarrow$ \\
$\pi^{M}$ & - & 0.204 & $0.224 \uparrow$ \\
Basis $_{Y}$ & -0.040 & $0 \uparrow$ & $0.020 \uparrow$
\end{tabular}

An agent in the no-leverage regime could choose to buy the cash-synthetic asset consisting of a portfolio of $Y$ and $C D S_{Y}$ - at a lower price than $X$ while earning the same return-but this portfolio is less valuable to agents because it cannot be used as collateral to back financial contracts. Thus, the cash-synthetic asset does not provide agents the ability to isolate payoffs in a state of the 
world. Similarly, every investor in the debt collateralization economy could sell $Y$ and $C D S_{Y}$ to buy $X$ at a price lower than the cash-synthetic asset. However, in equilibrium, no agent chooses to do so because the value of "downstream" contracts backed by $X$ is lower than those backed by $Y$, and it is also cheaper for the agent to buy $X$ while selling the $C D S_{Y}$ contract.

In fact, a positive basis could emerge in a leverage economy when there is a strong demand to use $Y$ to issue risky debt, rather than to use $Y$ to issue $C D S$, which is the equivalent leveraging with safe promises. To see this, consider the following comparative static for the economy above. Redistribute wealth from agents $h<h_{3}$ to agents $h>h_{1}$. For small redistribution, the only equilibrium variable affected would be $\eta$, the fraction of $Y$ used to back $C D S_{Y}$, and thus the supply of CDS. Taking wealth from agents $h<h_{3}$ would decrease demand for CDS, and increasing wealth for agents $h>h_{1}$ would increase demand for $Y / j_{M}$. A large enough redistribution would require $\eta=0$, at which point marginal agents and prices would change and the basis could be positive so that agents trading $X / C D S_{Y}$ would not trade $Y / C D S_{Y}$.

However, if agents could sell partially collateralized CDS, then a zero-basis would re-emerge because a issuing a partially collateralized CDS is equivalent to $Y / j_{M}$. Thus, the positive basis emerges with the restriction that CDS be fully collateralized because $X$ is "constrained" in the set of promises it can make while $Y$ is not. See Figure 8 for comparative statics regarding positive bases with leverage.

\section{C.5.2 Comparative Statics and Tail Risk}

We now consider how variations in the payoffs $M$ and $D$ affect the size of the basis in the economy with debt collateralization. Figure 12 plots the basis (multiplied by 100) with debt collateralization varying the payoffs $M$ and $D$. We parameterize beliefs as before (results are qualitatively the same for other belief structures). The comparative statics provides the following main qualitative results, which are interesting testable implications for our model. With debt collateralization the basis is more positive when tail risk is larger (when $D$ is small and $M$ is large). Debt collateralization endogenously shifts equilibrium so that investors purchase the asset only with the riskiest contract. When $M$ and $D$ are very different, leveraging the asset with a safe promise is not very valuable. Since debt collateralization endogenously increases the fraction of investors issuing expensive promises to buy the asset, with substantial tail risk, the collateral value of $Y$ substantially. Thus, 
variations in tail risk ought to correspond to variations in the size of the CDS basis.

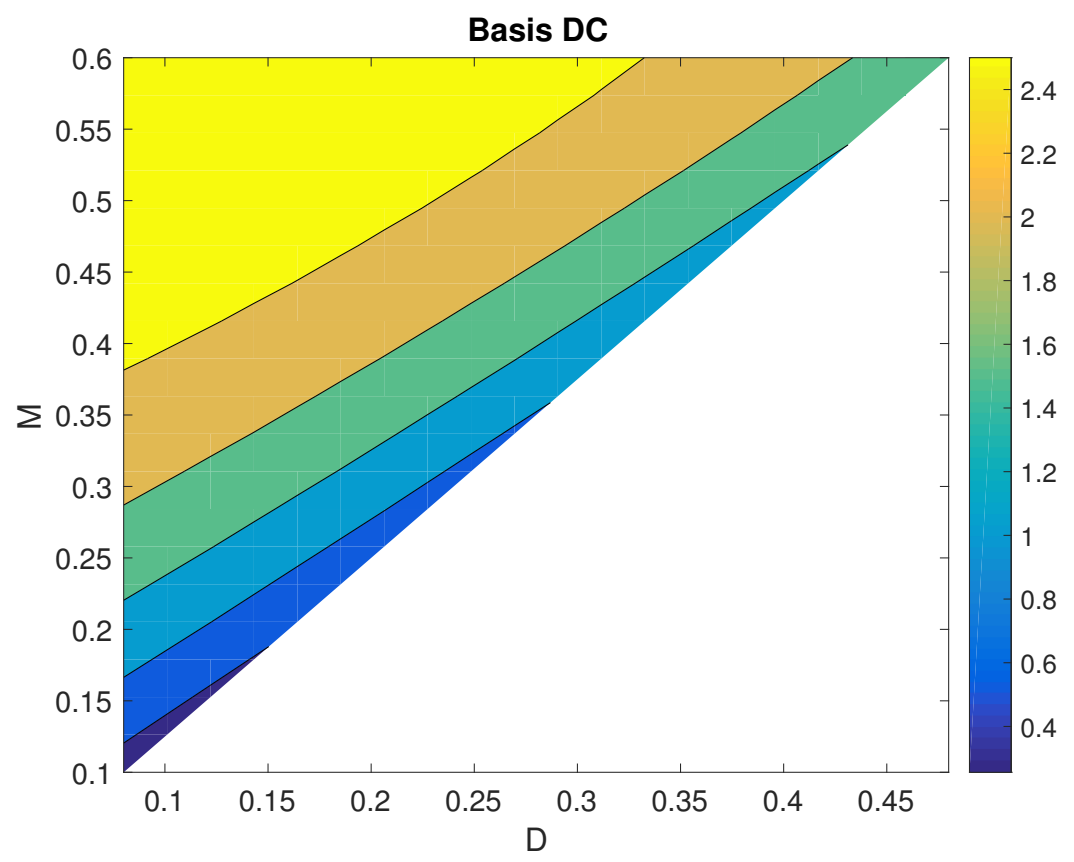

Figure 12: Comparative Statics with debt collateralization: basis (times 100) varying payoffs $M$, $D$.

\section{C.6 Equilibrium Conditions with $C D S_{M}$ and Leverage}

Proposition 5. Consider an economy with $C D S$ contracts $C D S_{Y}$ and $C D S_{M}$, which are backed by safe assets:

1. (Leverage) In an economy with level-0 contracts only, the basis on the risky debt is negative and the basis on the risky asset is non-negative. That is, $\pi^{M}+\pi_{C}^{M}<M$ and $p+\pi_{C}^{Y} \geq 1$.

2. (Pyramiding) In an economy with level-1 contracts, the basis on the risky debt is zero and the basis on the risky asset is positive, $\pi^{M}+\pi_{C}^{M}=M$ and $p+\pi_{C}^{Y}>1$

Marginal investors are given by equalizing expected return on two investment options. There are five marginal investors in equilibrium and they are as follows: agent $h_{1}$ is indifferent between buying $Y$ while making the $j_{M}$ promise and buying $Y$ while making the $j_{D}$ promise

$$
\frac{\gamma_{U}\left(h_{1}\right)(1-M)}{p-\pi^{M}}=\frac{\gamma_{U}\left(h_{1}\right)(1-D)+\gamma_{M}\left(h_{1}\right)(M-D)}{1-D-\pi_{C}^{Y}}
$$


Agent $h_{2}$ is indifferent between buying $X$ leveraged with the $C D S_{Y}$ contract and buying $X$ leveraged with the $C D S_{M}$ contract

$$
\frac{\gamma_{U}\left(h_{2}\right)(1-D)+\gamma_{M}\left(h_{2}\right)(M-D)}{1-D-\pi_{C}^{Y}}=\frac{\left(\gamma_{U}\left(h_{2}\right)+\gamma_{M}\left(h_{2}\right)\right)(M-D)}{M-D-\pi_{C}^{M}} .
$$

Agent $h_{3}$ is indifferent between holding $X$ to sell the $C D S_{M}$ contract and buying the risky debt $j_{M}$

$$
\frac{\left(\gamma_{U}\left(h_{3}\right)+\gamma_{M}\left(h_{3}\right)\right)(M-D)}{M-D-\pi_{C}^{M}}=\frac{\left(\gamma_{U}\left(h_{3}\right)+\gamma_{M}\left(h_{3}\right)\right) M+\gamma_{D}\left(h_{3}\right) D}{\pi^{M}} .
$$

Agent $h_{4}$ is indifferent between buying $j_{M}$ debt contract and buying the $C D S_{Y}$ contract

$$
\frac{\left(\gamma_{U}\left(h_{4}\right)+\gamma_{M}\left(h_{4}\right)\right) M+\gamma_{D}\left(h_{4}\right) D}{\pi^{M}}=\frac{\gamma_{M}\left(h_{4}\right)(1-M)+\gamma_{D}\left(h_{4}\right)(1-D)}{\pi_{C}^{Y}} .
$$

Agent $h_{5}$ is indifferent between buying the CDS on the risky asset and the CDS on the risky debt.

$$
\frac{\gamma_{M}\left(h_{5}\right)(1-M)+\gamma_{D}\left(h_{5}\right)(1-D)}{\pi_{C}^{Y}}=\frac{\gamma_{D}\left(h_{5}\right)(M-D)}{\pi_{C}^{M}}
$$

We obtain market clearing conditions by equating the supply and demand for a given asset. For any asset, agents demanding the asset will spend their endowment $(1+p)$ to buy the asset, at some price either with or without leverage. Market clearing for the safe asset $X$ requires

$$
\frac{\left(h_{1}-h_{2}\right)(1+p)}{1-\frac{\pi_{C}^{Y}}{1-D}}-\left(1-\frac{\left(1-h_{1}\right)(1+p)}{p-\pi^{M}}\right)+\frac{\left(h_{2}-h_{3}\right)(1+p)(M-D)}{M-D-\pi_{C}^{M}}=1
$$

Market clearing for the risky debt implies

$$
\frac{\left(h_{3}-h_{4}\right)(1+p)}{\pi^{M}}=\frac{\left(1-h_{1}\right)(1+p)}{p-\pi^{M}} .
$$

Market clearing for $C D S_{Y}$ guarantees

$$
\frac{\left(h_{4}-h_{5}\right)(1+p)}{\pi_{C}^{Y}}=\frac{\left(h_{1}-h_{2}\right)(1+p)}{1-D-\pi_{C}^{Y}}-\left(1-\frac{\left(1-h_{1}\right)(1+p)}{p-\pi^{M}}\right) .
$$


Finally, market clearing for $C D S_{M}$ necessitates

$$
\frac{h_{5}(1+p)}{\pi_{C}^{M}}=\frac{\left(h_{2}-h_{3}\right)(1+p)}{\left(M-D-\pi_{C}^{M}\right)} \text {. }
$$

Figure 13 illustrates the equilibrium regime with the direction of the arrow indicating the direction of funding. In general, pessimists lend to optimists in this economy. The most pessimistic agents buy the $C D S_{M}$ promise from moderates, thereby lending to agents holding $X / C D S_{M}$. Agents who are slightly less pessimistic hold $C D S_{Y}$, funding those who hold $X / C D S_{Y}$. Moderates buying the risky debt contracts lend to the most optimistic agents in the economy, who are buying $Y$ while making the $j_{M}$ promise. However, financial entanglement occurs between agents who hold $X / C D S_{Y}, Y / j_{D}$ or $X / C D S_{M}$; the safe debt contracts, $j_{D}$ are being bought by agents who hold $X$. Thus, within $\left(h_{1}, h_{2}\right)$, agents are (potentially) lending to each other, and agents in $\left(h_{2}, h_{3}\right)$ are also lending to those in $\left(h_{1}, h_{2}\right)$.

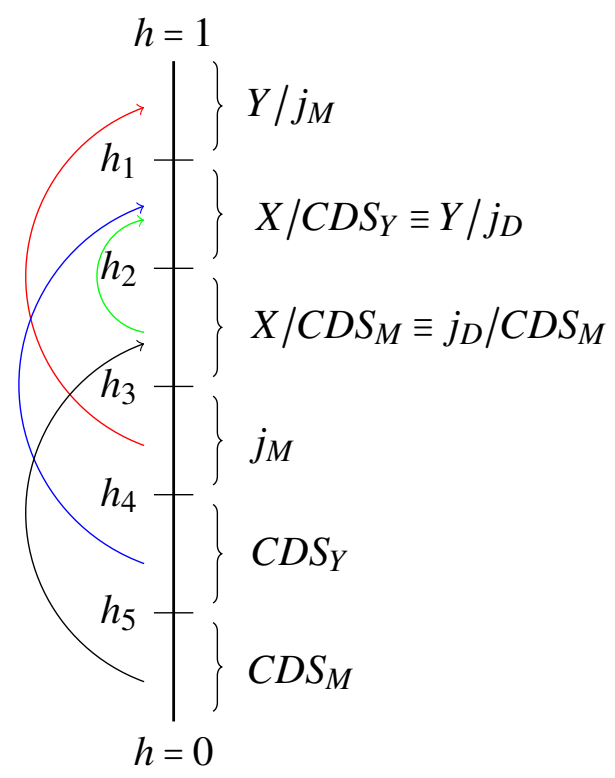

Figure 13: Equilibrium with $C D S_{Y}$ and $C D S_{M}$ (backed by $X$ ). No debt collateralization.

\section{C.7 Economy with $C D S_{M}$ and Pyramiding}

Figure 14 depicts the equilibrium regime and shows the direction of funding between agents. The borrower-lender relationships are similar to those in the previous regime. However, agents who 
are buying safe assets and selling the $C D S_{Y}$ contract are now lending to more pessimistic investors holding the risky debt contract with with leverage. This occurs because the safe debt issued by the moderates can be used as collateral to issue $C D S_{Y}$, which is a riskier position.

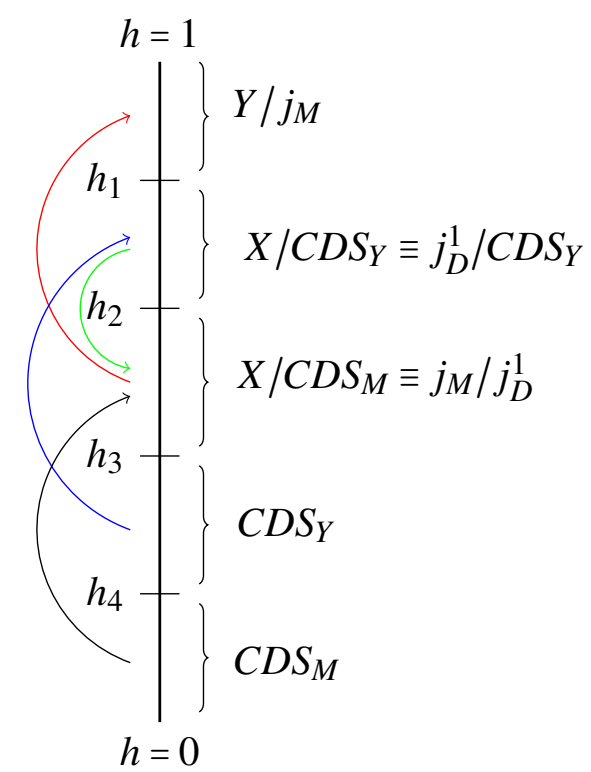

Figure 14: Equilibrium with $C D S_{Y}, C D S_{M}$, and Debt Collateralization.

\section{Marginal investors}

- $h_{1}$ : indifferent between $Y / j_{M}$ and $X / C D S_{Y}$

$$
\frac{\gamma_{U}\left(h_{1}\right)(1-M)}{p-\pi^{M}}=\frac{\gamma_{U}\left(h_{1}\right)(1-D)+\gamma_{M}\left(h_{1}\right)(M-D)}{1-D-\pi_{C}^{Y}}
$$

- $h_{2}$ : indifferent between $X / C D S_{Y}$ and $X / C D S_{M}$

$$
\frac{\gamma_{U}\left(h_{2}\right)(1-D)+\gamma_{M}\left(h_{2}\right)(M-D)}{1-D-\pi_{C}^{Y}}=\frac{\left(\gamma_{U}\left(h_{2}\right)+\gamma_{M}\left(h_{2}\right)\right)(M-D)}{M-D-\pi_{C}^{M}}
$$

- $h_{3}$ : indifferent between $X / C D S_{M}$ and $C D S_{Y}$

$$
\frac{\left(\gamma_{U}\left(h_{3}\right)+\gamma_{M}\left(h_{3}\right)\right)(M-D)}{M-D-\pi_{C}^{M}}=\frac{\gamma_{M}\left(h_{3}\right)(1-M)+\gamma_{D}\left(h_{3}\right)(1-D)}{\pi_{C}^{Y}}
$$


- $h_{4}$ : indifferent between $C D S_{Y}$ and $C D S_{M}$

$$
\frac{\gamma_{M}\left(h_{4}\right)(1-M)+\gamma_{D}\left(h_{4}\right)(1-D)}{\pi_{C}^{Y}}=\frac{\gamma_{D}\left(h_{4}\right)(M-D)}{\pi_{C}^{M}}
$$

\section{Market Clearing}

- Market for $Y$

$$
\frac{\left(1-h_{1}\right)(1+p)}{p-\pi^{M}}=1
$$

- Market for $C D S_{Y}$

$$
\frac{\left(h_{3}-h_{4}\right)(1+p)}{\pi_{C}^{Y}}=\frac{\left(h_{1}-h_{2}\right)(1+p)}{1-D-\pi_{C}^{Y}}
$$

- Market for $C D S_{M}$

$$
\frac{h_{4}(1+p)}{\pi_{C}^{M}}=\left(1+D-\frac{\left(h_{1}-h_{2}\right)(1+p)(1-D)}{1-D-\pi_{C}^{Y}}\right)\left(\frac{1}{M-D}\right)
$$

- Market for $X$ and $j_{M}$

$$
\frac{\left(h_{1}-h_{2}\right)(1+p)(1-D)}{1-D-\pi_{C}^{Y}}+\frac{\left(h_{2}-h_{3}\right)(1+p)(M-D)}{M-D-\pi_{C}^{M}}=1+M
$$

\section{C.7.1 Numerical Example}

Table 5 compares the prices and bases in the $C D S_{M}$ regime with leverage and the $C D S_{M}$ regime with equilibrium. The price of the risky asset increases because debt backed by $Y$ can now serve as collateral. The price of risky debt increases because agents can now buy the debt with leverage, increasing demand for risky debt. Furthermore, allowing $j_{M}$ to serve as collateral for non-contingent debt contracts increases the supply of safe assets in the economy. Since safe assets are used to issue both $C D S_{Y}$ and $C D S_{M}$, the supply of both these CDS contracts increase, resulting in a lower $\pi_{C}^{Y}$ and $\pi_{C}^{M}$.

\section{C.7.2 Double Basis in Four-State Economy}

While in the 3-state economy Basis $_{M}$ can never be positive because $j_{M}$ can be collateralized at most once, we can obtain a positive basis on both the risky debt in a four-state model in which 
Table 5: Double-Basis Equilibrium with Leverage and Debt Collateralization

\begin{tabular}{c|c|c} 
& Leverage & Collateralization \\
\hline$p$ & 0.502 & $0.527 \uparrow$ \\
$\pi^{M}$ & 0.196 & $0.223 \uparrow$ \\
$\pi_{C}^{Y}$ & 0.498 & $0.491 \downarrow$ \\
$\pi_{C}^{M}$ & 0.090 & $0.077 \downarrow$ \\
Basis $_{Y}$ & 0 & $0.018 \uparrow$ \\
Basis $_{M}$ & -0.014 & $0 \uparrow$
\end{tabular}

downstream debt contracts can be used to back multiple layers of debt. See Gong and Phelan (2019) for a theoretical characterization of debt collateralization with $N>3$ states.

The setup is as before, but now the set of states is given by by $S=\left(0, S_{1}, S_{2}, S_{3}, S_{4}\right)$, where $s=0$ is the initial state of the world at time $t=0$. Let the payout of the risky asset $Y$ be $\left(1, s_{2}, s_{3}, s_{4}\right)$ in states $\left(S_{1}, S_{2}, S_{3}, S_{4}\right)$, where $1>s_{2}>s_{3}>s_{4}$. Let $j_{i}$ be the debt contract promising $s_{i}$, and let the price of $j_{i}$ be $\pi^{i}$. We set $s_{2}=0.5, s_{3}=0.3, s_{4}=0.1$, and we let beliefs be given by $\gamma_{4}(h)=(1-h)^{3}$, $\gamma_{3}(h)=h(1-h)^{2}, \gamma_{2}(h)=h^{2}(1-h), \gamma_{1}(h)=1-\gamma_{4}(h)-\gamma_{3}(h)-\gamma_{2}(h)$, which preserves the properties in the three-state model.

Let there be full debt collateralization in the economy, and let there be a $\operatorname{CDS}$ on $Y$ (with price $\pi_{C}^{Y}$ ) and a CDS on $j_{2}$ (with price $\pi_{C}^{2}$ ). We let Basis $\alpha$ denote the basis on the asset $\alpha$. In equilibrium, $p=0.585, \pi^{2}=0.339, \pi^{3}=0.228, \pi_{C}^{Y}=0.431, \pi_{C}^{2}=0.169, \operatorname{Basis}_{Y}=0.016$, Basis $_{j_{2}}=0.009$, and we see a positive basis on both the risky asset and the risky debt.

\section{C.8 Equilibrium when $Y$ and $j_{D}$ cannot serve as collateral for CDS}

Let the set of financial contracts in the economy be given by $J=J^{X} \cup J^{Y}$, where $J^{X}$ consists of $C D S_{Y}$ backed by $X$ and $J^{Y}$ consists of non-contingent debt contracts. Note that we no longer allow $j_{D}$ to back $C D S_{Y}$. By Proposition 3, it must be the case that $\pi^{D}<D$ or no one will want to buy the safe debt. We define the basis on $j_{D}$, denoted $\operatorname{Basis}_{D}$, to be $D-\pi^{D}=\operatorname{Basis}_{D}$. Equilibrium features four marginal buyers, $h_{1}>h_{2}>h_{3}>h_{4}$. All agent $h>h_{1}$ will hold $Y / j_{M}$. Agents $h \in\left(h_{2}, h_{1}\right)$ will hold a combination of $X / C D S_{Y}$ and $Y / j_{D}$ (or just $X / C D S_{Y}$ if it is cheaper). $h \in\left(h_{3}, h_{2}\right)$ will sell their endowments to buy $j_{M}$ and $h \in\left(h_{4}, h_{3}\right)$ will buy $j_{D}$ instead. Finally, $h<h_{4}$ will hold only $C D S_{Y}$. Furthermore, we see a double basis in this case-one on the risky asset and one on the safe 
debt. Additionally, when $j_{D}$ is traded, the basis for $Y$ must be the same as the basis on $j_{D}$ because

$$
p-\pi^{D}=1-D-\pi_{C}^{Y} \Longrightarrow 1-p-\pi_{C}^{Y}=D-\pi^{D} \Longrightarrow \operatorname{Basis}_{Y}=\operatorname{Basis}_{D}
$$

Note that $j_{D}$ is not always traded in this equilibrium. Specifically, for low enough values of $M$, no agent strictly prefers to buy the safe debt. The intuition here is that a lower $M$ raises increases the payout of $C D S_{Y}$ in the $M$ state, making the CDS a more attractive option for moderate agents who wish to isolate payoffs in state $M$.

\section{C.9 Economies with Short Selling}

Thus far we have been silent about the possibility of short sales. One could understandably worry that, given the literature on limits to arbitrage, ignoring short selling would be a central driver of our results. We now show that this is not the case. In this section we provide agents the ability to sell short $Y$ and we show that in general agents will not choose to do so. The intuition for our result is that to bet against $Y$, a collateral-efficient strategy is to buy CDS (requiring no collateral) rather than to sell short the asset.

In addition to letting agents trade debt and CDS, now let agents also be allowed to issue a contract promising $(1, M, D)$, which we call a $Y$-promise. This $Y$-promise is collateralized by 1 unit of $X$ and costs $\pi_{\text {short }}^{Y}$. Note that buying $X$ and issuing a $Y$-promise is a collateralized short position in $Y$, which costs $1-\pi_{\text {short }}^{Y}$ and delivers $(0,1-M, 1-D)$, which is exactly the payoff to a CDS. Thus, agents can bet against $Y$ by either buying CDS or by shorting $Y$. However, a unit of $X$ can issue more CDS than $Y$-promise: one CDS is backed by $1-D$ units of $X$ as collateral while selling $Y$-promise requires one unit of $X$. This is precisely what we mean when we say that buying the CDS to bet against $Y$ is collateral efficient. ${ }^{20}$

We now reinforce our previous results by showing that our results hold even when short sales are allowed.

\footnotetext{
${ }^{20}$ An alternative modeling strategy follows Bottazzi et al. (2012) by explicitly requiring agents to borrow the asset $Y$ at a funding cost in order to sell it short in the market. This "box constraint" is how short sales are done in reality. They show that a binding box constraint leads to a liquidity premium (bonds are special in repo), increasing the cost of shorting. Our setup will deliver a similar result - the $Y$-promise may trade at a discount to $Y$, implying that shorting $Y$ entails a funding cost.
} 
Proposition 6. In an economy with short sales, suppose that agents can use $X$ to issue $Y$-promises, but these promises cannot be used as collateral.

1. (Shorting with no leverage) If $Y$ cannot be be used as collateral, then in equilibrium, agents do not issue $Y$-promises and the basis is negative.

2. (Shorting with leverage) If y can be used as collateral to issue debt contracts (but these debt contracts cannot serve as collateral), then in equilibrium, the basis on $Y$ is non-negative, as it was without short sales.

3. (Shorting with debt collateralization) If $Y$ can be used as collateral to issue debt, and these debt contracts can also be used as collateral, then in equilibrium the basis on $Y$ is strictly positive.

In all of these cases, it is important to note that more optimistic agents will always be willing to use $X$ as collateral for CDS because this position isolates payoffs in the $U$ and $M$ states. So the CDS on $Y$ is always traded.

In case 1 with no leverage, since neither $Y$ nor $Y$-promises can be used as collateral, investors are indifferent between buying $Y$ or the $Y$-promise. If the $Y$-promise is traded in equilibrium it must be that $\pi_{\text {short }}^{Y}=p$. Since buying $X$ and issuing a $Y$-promise delivers the same payoffs as buying a CDS, a $Y$-promise will be issued in equilibrium only if $\pi_{C}^{Y}=1-\pi_{\text {short }}^{Y}$, implying that $p+\pi_{C}^{Y}=1-$ that is, the basis is zero. But, we have already shown that the basis is strictly negative when $X$ can issue CDS and $Y$ cannot be leveraged since $X$ has higher collateral value (the proof of 4 still holds with short-selling). This contradiction implies that in equilibrium, no agent will trade the $Y$-promise. The intuition for the result is immediate: when $Y$ cannot be used as collateral, the basis is negative ( $Y$ is cheap) and so investors do not want to sell short the already-cheap asset, but those who wish to bet against it do so by buying CDS.

In case 2 with leverage, because $Y$ can be used as collateral while the $Y$-promise cannot, it must be that $\pi_{\text {short }}^{Y} \leq p$ if the $Y$-promise is traded. Suppose that short sales do occur in equilibrium. As we just argued, agents are only willing to issue $Y$-promises (to short $Y$ ) if the basis is nonnegative since a negative basis implies it is cheaper to buy CDS. Thus, the presence of short-sales imply a non-negative basis. In particular, the equilibrium regime would feature a set of agents 
buying $Y$ promises with these agents lying between those using $X$ to issue CDS and those buying the risky debt. Even if short sales do not occur, then the equilibrium regime is exactly as discussed in the previous section so the basis is non-negative. The result in case 3 with debt collateralization follows from the same argument.

The restriction that $Y$-promises cannot be completely collateralized as the underlying asset can reflect either (i) direct limitations in borrowing underlying assets to short or (ii) the fact that assets that are used in CDOs or other structured securities cannot be replicated frictionlessly to be used in these same structures. (Technically, the result holds when the $Y$-promise can be collateral but the debt backed by the $Y$-promise cannot be, implying that a risky promise backed by the $Y$ promise would be different from the risky promise backed by $Y$.) These restrictions are empirically relevant given the assets we have in mind (corporate bonds, mortgage- and asset-backed securities, etc.).

\section{C.10 Additional Proofs}

Proof of Proposition 4. We prove for each case.

Case 1, No leverage: From Lemma 3, the position $X / C D S_{Y}$ must be traded in equilibrium, otherwise no agent will hold $X$. Thus $X / C D S_{Y}$ cannot be more expensive than $Y / C D S_{Y}$. Hence, it must be that $1-D-\pi_{C}^{Y} \leq(1-D) p-D \pi_{C}^{Y}$, which simplifies to $1 \leq \pi_{C}^{Y}+p$. In order for any agent to hold $j_{D}$, which offers the same payoff as $X$ but which cannot be used as collateral, it must be that $\pi^{D}<D$ in equilibrium. But since $\pi_{C}^{Y}+p \geq 1$, then $p-\pi^{D}>(1-D) p-D \pi_{C}^{Y}$, which means that agents would strictly prefer to use $Y$ to issue CDS rather than to issue debt.

Case 2, Leverage and limits on $Y$ : Consider the agent $h$ who is indifferent between holding $X / C D S_{Y}$ and holding $Y$. For $h, \mathbb{E}_{h}[X / C D S Y]=\mathbb{E}_{h}[Y]$, thus

$$
\frac{\gamma_{U}(h)+\gamma_{M}(h) M+\gamma_{D}(h) D}{p}=\frac{\gamma_{U}(h)(1-D)+\gamma_{M}(h)(M-D)}{1-D-\pi_{C}^{Y}}
$$

Furthermore, this agent is relatively optimistic and strictly prefers both of these two options to holding the safe asset, $X$. It follows that

$$
\frac{\gamma_{U}(h)(1-D)+\gamma_{M}(h)(M-D)}{1-D-\pi}>1
$$


Rearranging and simplifying Equation 35, we have that

$$
p+\pi_{C}^{Y}=(1-D)+\frac{D(1-D-\pi)}{\gamma_{U}(h)(1-D)+\gamma_{M}(h)(M-D)} .
$$

Combining this with $36, p+\pi_{C}^{Y}<(1-D)+D=1 \Longrightarrow p+\pi_{C}^{Y}<1$.

Case 3, Leverage, no limits on $Y$ : First, suppose $\bar{\ell}=D$. Then in equilibrium investors must be indifferent between $X / C D S$ and $Y / j_{D}$ (the alternative is investors will hold $Y$ without leverage, in which case the basis is negative per earlier results). Since the payoffs to these positions are the same, the costs of these positions are the same, $1-D-\pi_{C}^{Y}=p-\pi_{D}$, implying the basis is $\pi_{D}-D$, which is negative since the safe debt cannot be used as collateral while $X$ can. Note that if $D<\bar{\ell}<M$ and safe debt is issued in equilibrium, then the same argument implies the basis is negative.

If $\bar{\ell}<D$ then investors are ordered $X / C D S, Y / j_{\bar{\ell}}, j_{\bar{\ell}}, C D S$. The position $Y / j_{\bar{\ell}}$ pays $(1-D+D-$ $\bar{\ell}, M-D+D-\bar{\ell}, D-\bar{\ell})$. This position can be replicated using $X / C D S$ and buying $\frac{D-\bar{\ell}}{\bar{\ell}}$ units of $j_{\bar{\ell}}$. Note that the investor indifferent between $Y / j_{\bar{\ell}}$ and $j_{\bar{\ell}}$ is indifferent between buying and selling $j_{\bar{\ell}}$, but strictly prefers $Y / j_{\bar{\ell}}$ over $X / C D S$. Thus, the position must be cheaper:

$$
1-D+\pi_{C}^{Y}+\frac{D-\bar{\ell}}{\bar{\ell}} \pi^{\bar{\ell}}>p-\pi^{\bar{\ell}}
$$

Since $\bar{\ell}<D$ and $\pi^{\bar{\ell}}<\bar{\ell}, D\left(\frac{\pi^{\bar{\ell}}}{\bar{\ell}}-1\right)<0$, and the basis satisfies

$$
p+\pi_{C}^{Y}<1-D+D\left(\frac{\pi^{\bar{\ell}}}{\bar{\ell}}-1\right)<1
$$

Proof of Lemma 3. Suppose some agent strictly prefers to hold only the safe asset $X$ without selling any financial contracts. Let $\mathbb{E}_{h}[a]$ denote the expected return on holding the position $a$. Then there exists some agent $h$ such that $\mathbb{E}_{h}[X]>\mathbb{E}_{h}[X / C D S]$. This implies that:

$$
1>\frac{\gamma_{U}(h)+\gamma_{M}(h)\left(\frac{M-D}{1-D}\right)}{1-\frac{\pi_{C}^{Y}}{1-D}} \Longrightarrow(1-D)-\pi_{C}^{Y}>\gamma_{U}(h)(1-D)+\gamma_{M}(h)(M-D) \text {. }
$$


Additionally, since $h$ strictly prefers to hold $X$, it must be the case that $\mathbb{E}_{h}[X]>\mathbb{E}_{h}\left[C D S_{Y}\right]$, implying

$$
1>\frac{\gamma_{M}(h)(1-M)+\gamma_{D}(h)(1-D)}{\pi_{C}^{Y}} \Longrightarrow \pi_{C}^{Y}>\gamma_{M}(h)(1-M)+\gamma_{D}(h)(1-D)
$$

Note that adding together equations 37 and 38 implies the following contradiction:

$$
(1-D)>(1-D)\left(\gamma_{U}(h)+\gamma_{M}(h)+\gamma_{D}(h)\right) \Longrightarrow(1-D)>(1-D)
$$

Thus, no agent ever prefers to hold $X$. By risk neutrality, it is also follows that any agent who choses to sell CDS will sell as many units of CDS as they can. To see that no agent is willing to hold the cash-synthetic asset, suppose for contradiction that some agent $h$, strictly prefers the cash-synthetic asset. That is, $\mathbb{E}_{h}\left[Y+C D S_{Y}\right]>\mathbb{E}_{h}[Y]$ Then,

$$
\frac{1}{p+\pi_{C}^{Y}}>\frac{\gamma_{U}(h)+\gamma_{M}(h) M+\gamma_{D}(h) D}{p} \Longrightarrow p>\left(p+\pi_{C}^{Y}\right)\left(\gamma_{U}(h)+\gamma_{M}(h) M+\gamma_{D}(h) D\right)
$$

Additionally, we must also have, $\mathbb{E}_{h}\left[Y+C D S_{Y}\right]>\mathbb{E}_{h}\left[C D S_{Y}\right]$, which means

$$
\frac{1}{p+\pi_{C}^{Y}}>\frac{\gamma_{M}(h)(1-M)+\gamma_{D}(h)(1-D)}{\pi_{C}^{Y}} \Longrightarrow p>\left(p+\pi_{C}^{Y}\right)\left(\gamma_{M}(h)(1-M)+\gamma_{D}(h)(1-D)\right)
$$

Combining the above two inequalities yields the following contradiction:

$$
p+\pi_{C}^{Y}>\left(p+\pi_{C}^{Y}\right)\left(\gamma_{U}(h)+\gamma_{M}(h)+\gamma_{D}(h)\right) \Longrightarrow p+\pi_{C}^{Y}>p+\pi_{C}^{Y}
$$

Proof of Lemma 5. First note that because the minimum payout of $Y$ is $D$ and the maximum payout of $C D S_{Y}$ is $1-D$, each unit of $Y$ can back $\frac{D}{1-D}$ units of $C D S_{Y}$. The payoff of buying one unit of $Y$ and selling $\frac{D}{1-D}$ units of $C D S_{Y}$ (holding $\left.Y / C D S_{Y}\right)$ is $\left(1, \frac{M-D}{1-D}, 0\right)$ in states $(U, M, D)$. However, this return is equivalent to holding $Y$ and selling $j_{D}$, so the choice-set of agents has not been increased by this financial innovation.

Now consider when $j_{D}$ could also be used to back $C D S_{Y}$. Without letting agents use $Y$ to issue $C D S_{Y}$, agents holding $Y$ were still able to do this indirectly by selling the promising $j_{D}$. One unit 
of $j_{D}$ can back $\frac{D}{1-D}$ units of $C D S_{Y}$, which is the exactly the amount issued when agents holding $Y$ issue $C D S_{Y}$ directly. In short, the leverage equilibrium, as we have characterized, does not depend on which assets can back $C D S_{Y}$.

Proof of Corollary 4. From previous theorem, we have that $p+\pi_{C}^{Y}>1 \Longrightarrow p>1-\pi_{C}^{Y} \Longrightarrow p-$ $D>(1-D)-\pi_{C}^{Y}$. Note that $1-D-\pi_{C}^{Y}$ is the cost of holding $X / C D S_{Y}$ while $p-D$ is the cost of holding $Y / j_{D}$. Thus, all agents will choose the cheaper option and hold $X$ while selling the $C D S_{Y}$ contract.

Proof of Lemma 6. There are two parts to this proof. First we will show that no one holds $Y / C D S_{Y}$. Second, we will show that no agent strictly prefers to hold $j_{M} / C D S_{Y}$. Note that we know that $1-D-\pi_{C}^{Y}<p-D$ and hence $p+\pi_{C}^{Y}>1$. Then,

$$
\Longrightarrow\left(p+\pi_{C}^{Y}\right)(1-D)>1-D \Longrightarrow p-\frac{D}{1-D} \pi_{C}^{Y}>1-\frac{1}{D} \pi_{C}^{Y}
$$

So, the cost of holding $Y / C D S_{Y}$ is higher than the cost of holding $X / C D S_{Y}$ even though these two positions have equivalent returns. Thus, no agent will choose to hold $Y / C D S_{Y}$.

Now, suppose for contradiction that there is an agent, $h$ who strictly prefers to hold $j_{M} / C D S_{Y}$. This means that for investor $h$, the expected return of $j_{M} / C D S_{Y}$ must be greater than the return of $X / C D S_{Y}$. Thus,

$$
\frac{\gamma_{U}(h) M(1-D)+\gamma_{M}(h)(M-D)}{(1-D) \pi^{M}-D \pi_{C}^{Y}}>\frac{\gamma_{U}(h)(1-D)+\gamma_{M}(h)(M-D)}{1-D-\pi_{C}^{Y}}
$$

Rearranging this equation and simplifying, we obtain

$$
\begin{aligned}
& \gamma_{U}(h) M(1-D)+\gamma_{M}(h)(M-D)> \\
& \pi^{M}\left(\gamma_{U}(h)(1-D)+\gamma_{M}(h)(M-D)\right)+\pi_{C}^{Y}(M-D)\left(\gamma_{U}(h)+\gamma_{M}(h)\right) .
\end{aligned}
$$

Since $h$ strictly prefers $j_{M} / C D S_{Y}$, the expected payout of this position must also be higher than the expected payout of holding $j_{M} / j_{D}^{1}$. So,

$$
\frac{\gamma_{U}(h) M(1-D)+\gamma_{M}(h)(M-D)}{(1-D) \pi^{M}-D \pi_{C}^{Y}}>\frac{\gamma_{U}(h)(1-D)+\gamma_{M}(h)(M-D)}{1-D-\pi_{C}^{Y}}
$$


Rearranging and simplifying the above, we obtain

$$
\begin{aligned}
-\left(\gamma_{U}(h) M(1-D)+\right. & \left.\gamma_{M}(h)(M-D)\right)> \\
& -\pi^{M}\left(\gamma_{U}(h)(1-D)+\gamma_{M}(h)(M-D)\right)-\pi_{C}^{Y}(M-D)\left(\gamma_{U}(h)+\gamma_{M}(h)\right) .
\end{aligned}
$$

Combining Equations (43) and (46) yields $0>0$, a contradiction. So, there does not exist a set of agents with positive measure who strictly prefer to sell $C D S_{Y}$ backed by $j_{M}$.

Proof of Proposition 5. We prove the result in the three-state economy for each case.

Case 1, Leverage. Consider the agent who is indifferent between holding $X / C D S_{M}$ and $j_{M}$. Since this agent is relatively optimistic, the expected return of both of these two options must be greater than 1 . Then, we have that $\mathbb{E}_{h}\left[X / C D S_{M}\right]=\mathbb{E}_{h}\left[j_{M}\right]>1$.

$$
\frac{\left(\gamma_{U}(h)+\gamma_{M}(h)\right)(M-D)}{M-D-\pi_{C}^{M}}=\frac{\left(\gamma_{U}(h)+\gamma_{M}(h)\right) M+\gamma_{D}(h) D}{\pi^{M}}>1 .
$$

Rearranging and simplifying 47, we obtain

$$
\begin{gathered}
\left(\pi^{M}+\pi_{C}^{M}\right)\left(\gamma_{U}(h)+\gamma_{M}(h)\right)(M-D)=D\left(M-D-\pi_{C}^{M}\right)+(M-D)^{2}\left(\gamma_{U}(h)+\gamma_{M}(h)\right) \\
\Longrightarrow \pi^{M}+\pi_{C}^{M}=\frac{D\left(M-D-\pi_{C}^{M}\right)}{\left(\gamma_{U}(h)+\gamma_{M}(h)\right)(M-D)}+M-D .
\end{gathered}
$$

Combining the above with Equation 47, it follows that $\pi^{M}+\pi_{C}^{M}<M$.

Case 2, Debt Collateralization. Because $X / C D S_{M}$ is equivalent to $j_{M} / j_{D}^{1}$, any equilibrium in this economy must feature a zero basis on $j_{M}\left(\operatorname{Basis}_{M}=0\right)$. A positive basis, Basis $_{M}>0$ would imply that $j_{M} / j_{D}^{1}$ is expensive relative to $X / C D S_{M}$ and no agent would want to buy $j_{M}$. This is not an equilibrium because optimists who want to isolate payoffs in state $U$ would be willing to sell $j_{M}$ at a lower price, driving the basis toward 0. A negative basis, $\operatorname{Basis}_{M}<0$ is not an equilibrium because this implies $j_{M} / j_{D}^{1}$ is cheap relative to $X / C D S_{M}$ and $C D S_{M}$ is never issued as a result. However, extreme pessimists who want to isolate payoffs in state $D$ and would therefore be willing to buy $C D S_{M}$ even at a higher price, driving the basis toward 0. 